\title{
Review: The Comparison of Clay Modifier (Cloisite Types) in Various Epoxy-Clay Nanocomposite Synthesis Methods
}

\author{
Muhammad Yunus Firdaus 1,", Herlinda Octaviani ${ }^{1}$, Humaira Herlini ${ }^{1}$, Nurul Fatimah ${ }^{1}$, \\ Tika Mulyaningsih ${ }^{1}$, Zachnaz Fairuuz ${ }^{1}$ and Dr. Eng. Asep Bayu, ST, M. Eng ${ }^{1}$. \\ ${ }^{1}$ Department of Chemistry Education, Faculty of Mathematics and Science Education, Universitas Pendidikan \\ Indonesia, J1. Dr. Setiabudi no 229, Bandung 40154, West Java, Indonesia
}

\begin{abstract}
Nanocomposites are a new material discovery in the 21st century. One of the nanocomposite materials which are useful in life is epoxy-clay nanocomposites. Epoxy clay nanocomposites have a reasonably wide application in industrial fields such as aerospace, defense, automobile, etc. The purpose of writing this review is to conduct a literature review on mechanical properties in various Cloisite as a filler of Epoxy-clay Nanocomposites. There are several examples of cloisite, namely Cloisite 10A, Cloisite 15A, Cloisite 20A, Cloisite 25A, Cloisite 30B, and Cloisite 93A. Cloisite has the advantage of producing mechanical properties, especially in the tensile modulus and strength, which is more increased than conventional reinforcing materials. These methods' synthesis results were then characterized using TEM, SEM, XRD, and other tests to determine their mechanical properties. The material parameters resulting from nanocomposites' synthesis are well seen from the high Tensile strength and modulus values. The highest increase in mechanical properties was found in the cloisite $93 \mathrm{~A}$ by the ultrasonic synthesis method or mechanical stirring based on the study results.
\end{abstract}

Keywords: nanocomposite; organoclay; epoxy resin; synthesis; Cloisites.

\section{Introduction}

Recently, clay-polymer nanocomposites are being widely used in industrial applications. These innovative materials are at the crossroads of several scientific disciplines. There is a very high demand for material with high performance. Therefore nanocomposites are used to replace conventional materials in future engineering applications ${ }^{1}$. One of the nanocomposite materials which are useful in life is epoxy-clay nanocomposites.

Epoxy resin is a thermosetting polymer with a distinct three-ring epoxide group known as an oxirane or epoxy ring that is highly strained and reactive. This epoxide group's molecular base can be varied widely, resulting in the diversity of molecular structure and thus various classes of epoxy resins ${ }^{2-4}$. Epoxy resins are generally utilized for coatings, adhesives, paints, etc., owing to their exclusive properties. But the showing insufficient toughness, low crack resistance due to the highly cross-linked structure, and brittleness nature confine their application in certain $\operatorname{areas}^{5}$.

One of the crucial properties of clay is its ability to improve polymer properties significantly. Clay reinforcement offers higher resistance against straining due to their higher module because it will carry the major portion of applied load to the nanocomposite under stress conditions ${ }^{6}$. The dispersion of clay nanofillers and the control of polymer particle interactions are the successful parameters of polymer clay nanocomposite applications ${ }^{7}$. Due to its excellent enhancement, the nanofiller can be loaded even at small contents. In its nanoscale, nanoparticles appear with a high surface area, thus possibly disrupting the polymer chains' mobility, which produces traits that can be manipulated ${ }^{8}$. Factors that can influence the role of nanoparticles as fillers in the polymer matrix are: fillers should have excellent mechanical properties such as strength and Young's modulus; they should be well dispersed and avoid agglomeration; they should have a high aspect ratio and high surface area to enable interaction with the polymer ${ }^{9}$.

The dispersion of clay in the polymer matrix becomes a problem with covalent bonds between the clay sheet interlayer. In order to solve this problem, clay particles are modified before being dispersed into the polymer matrix. During the modification process, the spacing between the clay particle interlayers was increased by surfactant intercalation or grafting of hydrophobic functional moieties. This allows the hydrophobic properties to be incorporated into the clay particles to be well dispersed in the polymer matrix ${ }^{8}$. By modification of nano clay and the reduction of particles' hydrophilicity, the gallery distance between silicate layers of nano clay can be increased, so penetration of polymeric chains through 
them can become more comfortable, and consequently stacks will be reduced ${ }^{10}$.

The modifier such as ammonium salts has long alkyl chains for compatibilization of organoclays with hydrophobic polymer matrices. However, others are reactive and functionalized with monomeric units, radical (photo)polymerization and atom transfer radical polymerization initiating groups, and reactive epoxy groups to cure and reinforce epoxy resins ${ }^{11}$. The functionalization of nanoclay is carried out to reach high properties of nanocomposites and benefit from the nanoclays ${ }^{12}$.

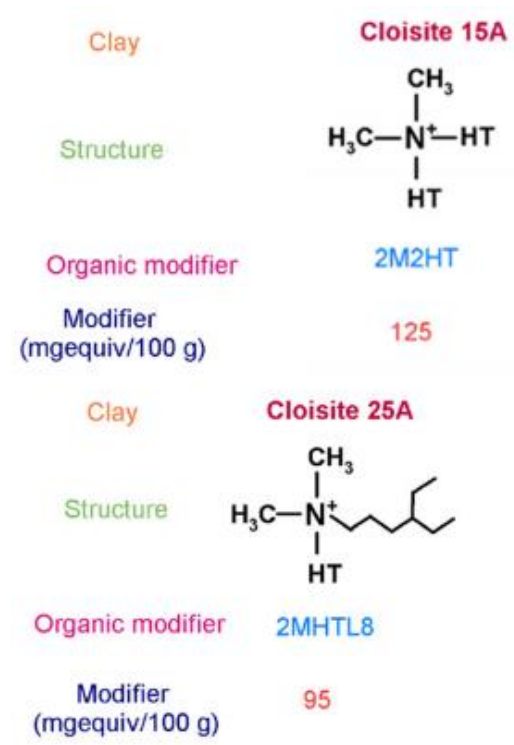

The smectite is included in the 2:1 phyllosilicate category with an octahedral alumina layer structure, fused between the silica layers present in a tetrahedral arrangement ${ }^{7}$. Montmorillonite (MMT) is a subclass of clay smectite widely used as reinforcement in polymer matrices because it has a high surface area with good reactivity when modified, so it is compatible for polymer exfoliation and intercalation in the interlayer region. MMT is a silicate layer with a platelet-like shape. A modified form of MMT clay with a quaternary ammonium surfactant called "Cloisite". Cloisite is widely used as a filler in polymer matrices ${ }^{8}$.

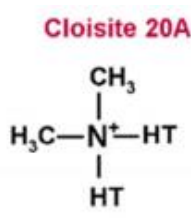

$2 \mathrm{M} 2 \mathrm{HT}$

95<smiles>C[N+]1(CCO)CCOP1</smiles>

MT2EtOH

90<smiles>C[NH+]([InH2])[IH]</smiles>

Cloisite 10A<smiles>C[N+](C)(C)Cc1ccccc1</smiles>

2MBHT

125

Figure 1. Structure of different types of Cloisite. $\mathrm{T}$ is Tallow $(\sim 65 \% \mathrm{C} 18 ; \sim 30 \% \mathrm{C} 16 ; \sim 5 \% \mathrm{C} 14)$, and HT is Hydrogenated Tallow ${ }^{8}$

As shown in Figure 1 above, there are several examples of cloisite, namely Cloisite 10A, Cloisite 15A, Cloisite 20A, Cloisite 25A, Cloisite 30B, and Cloisite 93A. In Cloisite 30B and Cloisite 10A, the formation of intercalated organoclay/poly (butylene terephthalate) nanocomposites was carried out, leading to an increase in tensile ${ }^{8}$. MMT modified with organic compounds is attracting wide attention as new materials with increasing utilization. This organic/inorganic hybrid material is found as environmental and industrial applications such as organic pollutant adsorbents ${ }^{13-15}$ or as fillers in clay nanocomposites ${ }^{16-20}$.

Cloisite 30B (C30B) modification was carried out to improve the interfacial interaction between the nanoclay and the polymer matrix. The 2-hydroxyethyl group could increase the chemical compatibility with a relatively polar polymer ${ }^{21}$. The presence of $\mathrm{C} 30 \mathrm{~B}$ as a filler in thermoset polymers can form layered structures, and the hydroxyl group can make its interaction with the polymer matrix more useful ${ }^{22}$.

When clay paste passes from the "rigid gel" to the "soft gel," this change is called the third step of swelling. When "soft gel" gives a suspension to the ground state, it is no longer part of the swelling. Still, it is the so-called sol-gel transition, which is important in clay studies and applications, such as dynamic light scattering alteration, fluidity loss, and fluorescence enhancement ${ }^{23}$. Hydroxylation is conducted at basic medium ${ }^{24}$. With moderate alkali activation at $\mathrm{pH}<5$, the adsorptive removal capability for methylene blue was improved. Indeed, this alkali activation can moderately break the SieOeM and SieOeSi bonds and remove the metal cations. Si in the crystal backbone of phyllosilicate by which new adsorption sites were created and the negative surface charges were increased. In contrast, some acid treatment leads to an effective modification method to increase clay's surface area. However, note that moderate acidic modification can be an inexpensive and effective method to increase the surface area of clay ${ }^{25}$.

Exfoliated structures have been shown to yield

optimized physical and mechanical properties. Their development depends on the resin and nanoclay types as well as the preparation methods. The mixing method has a significant effect on the morphology of unsaturated polyester-nanoclay composites. The amount of optimum silicate loading that results in the exfoliated structure is highly dependent on the mixing process. Utilizing high shear mixing and 
ultrasonication led to better dispersion of polymer chains into nanoclay platelets; accordingly, this resulted in improved mechanical properties ${ }^{26}$. Various types of methods can be used to synthesize epoxy-clay nanocomposites to disperse the nanoclay, namely the Slurry Compounding method, Ultrasonication High-Shear Mixing, and Mechanical Stirring.

Many studies have been conducted based on the synthesis method. However, clay selection is indispensable for the process of making epoxy clay nanocomposites. Cloisite has the advantage of producing mechanical properties, especially in the tensile modulus and strength which is more increased than conventional reinforcing materials. Thus, the purpose of writing this review is to conduct a literature review on the type of cloisite in various epoxy-clay nanocomposite synthesis methods. The nanocomposite system studied was the nano-sized organoclay as reinforcement in the epoxy polymer matrix. The synthesized nanocomposites were characterized using TEM, SEM, XRD, and other tests to determine their mechanical properties. The cloisite material parameters produced from nanocomposites' synthesis were seen from the high Tensile Modulus and Strength values. Writing this review is expected to help the industry and researchers to develop more advanced epoxy-clay materials. The methods, materials, and tensile test results of the journals reviewed can be seen in Table 1 below.

Table 1. Comparison of the mechanical properties of several epoxy-clay nanocomposites.

\begin{tabular}{|c|c|c|c|c|c|}
\hline Nanoclay & $\begin{array}{c}\text { Nanoclay } \\
\text { concentration }\end{array}$ & $\begin{array}{l}\text { Synthesis } \\
\text { Method }\end{array}$ & $\begin{array}{c}\text { Tensile Strength } \\
(\%)\end{array}$ & $\begin{array}{c}\text { Tensile Modulus } \\
(\%)\end{array}$ & Ref. \\
\hline \multirow[t]{2}{*}{ Cloisite 10A } & $2 \mathrm{wt} \%$ & $\begin{array}{l}\text { High Shear } \\
\text { Mixing }\end{array}$ & 22 & 5 & $\begin{array}{l}\text { P. Mathivanan } \\
\text { et al. }{ }^{27}\end{array}$ \\
\hline & $3 \mathrm{wt} \%$ & $\begin{array}{l}\text { High Shear } \\
\text { Mixing and } \\
\text { Ultrasonication }\end{array}$ & 34.47 & 50 & $\begin{array}{c}\text { H. Salam et } \\
\text { al. }{ }^{28}\end{array}$ \\
\hline \multirow{3}{*}{ Cloisite 15A } & $1 \mathrm{wt} \%$ & Ultrasonication & 9.96 & 3.09 & Singh et al. ${ }^{29}$ \\
\hline & $1 \mathrm{wt} \%$ & Ultrasonication & 16.36 & 6.36 & Singh et al. ${ }^{30}$ \\
\hline & $2 \mathrm{wt} \%$ & Ultrasonication & 11.75 & 5.43 & $\begin{array}{c}\text { Sharma, B., et } \\
\text { al. } 31\end{array}$ \\
\hline \multirow{2}{*}{ Cloisite 20A } & $3 \mathrm{wt} \%$ & $\begin{array}{l}\text { High shear } \\
\text { mixing }\end{array}$ & 24 & 2.6 & $\begin{array}{l}\text { Ramakrishnan, } \\
\text { S. et al. }{ }^{32}\end{array}$ \\
\hline & $5 \mathrm{wt} \%$ & Ultrasonication & 29.6 & 23.4 & $\begin{array}{l}\text { Merah and } \\
\text { Mohamed }^{33}\end{array}$ \\
\hline \multirow{2}{*}{ Cloisite 25A } & $2 \mathrm{wt} \%$ & $\begin{array}{l}\text { Mechanical } \\
\text { Stirring and } \\
\text { Ultrasonication }\end{array}$ & 33.39 & 15.88 & Kumar et al. ${ }^{34}$ \\
\hline & $2 \mathrm{wt} \%$ & $\begin{array}{c}\text { Mechanical } \\
\text { Stirring and } \\
\text { Ultrasonication }\end{array}$ & 4.97 & 50.81 & Kumar et al. ${ }^{35}$ \\
\hline \multirow[t]{2}{*}{ Cloisite 30B } & $4 \mathrm{wt} \%$ & $\begin{array}{l}\text { Ultrasonication } \\
\text { and Mechanical } \\
\text { stirring }\end{array}$ & 10 & 4.65 & $\begin{array}{l}\text { Mustapha et } \\
\text { al. } 37\end{array}$ \\
\hline & $5 \mathrm{wt} \%$ & $\begin{array}{l}\text { Internal Stirrer, } \\
\text { Melting Method }\end{array}$ & 37 & 49 & Sharifi et al. ${ }^{36}$ \\
\hline \multirow{4}{*}{ Cloisite 93A } & $2.5 \mathrm{wt} \%$ & $\begin{array}{l}\text { Mechanical } \\
\text { stirring }\end{array}$ & 63.62 & 44.17 & Kumar $^{5}$ \\
\hline & $4 \mathrm{wt} \%$ & $\begin{array}{l}\text { Mechanical } \\
\text { stirring and } \\
\text { Ultrasonication }\end{array}$ & -5.08 & 31.82 & $\begin{array}{l}\text { M. Sanchez- } \\
\text { Cabezudo et } \\
\quad \text { al. }{ }^{38}\end{array}$ \\
\hline & $2.5 \mathrm{wt} \%$ & Ultrasonication & 67 & 37 & $\begin{array}{l}\text { Sudheer } \\
\text { Kumar }^{39}\end{array}$ \\
\hline & $5 \mathrm{wt} \%$ & $\begin{array}{l}\text { Mechanical } \\
\text { stirring and } \\
\text { Ultrasonication }\end{array}$ & 23.58 & 23.66 & $\begin{array}{l}\text { R. Jeyakumari } \\
\text { et al. }{ }^{40}\end{array}$ \\
\hline
\end{tabular}




\section{Review of the literature}

\subsection{Cloisite 10A}

Epoxy is the preferred material and is widely used for industrial applications, usually as fiber-reinforced composites. Epoxy is one of the most important thermosetting resins used as a matrix material for polymer-based composites. Its low density (1.3 $\mathrm{g} / \mathrm{cm} 3$ ) has excellent bonding capabilities and good mechanical properties ${ }^{4,41,42}$. Fiber-reinforced polymer composites (FRP) have good static mechanical properties but less impact strength ${ }^{43-46}$. Most FRPs generally use reinforcements such as fiberglass, aramid fiber, etc., with epoxy as the matrix ${ }^{47,48}$. The majority of polymer reinforced fibers (FRPs) consist of an epoxy matrix reinforced with glass fibers. Epoxy-clay based GFRP nanocomposites have high specific strength ${ }^{49}$. Epoxy-based glass fiber reinforced plastics (epoxy-based GFRP) exhibit good specific stiffness/strength and are used in many structural applications $43,44,50,51$.

P. Mathivanan and S. Thirugnanam ${ }^{25}$ stated that the Aluminum-Glass Fiber epoxy resin panels with resin modification by Cloisite $10 \mathrm{~A}$ were successfully manufactured. The selection of a montmorillonite organoclay such as Cloisite 10A suggests that this nanoclay is a promising candidate for reinforcement in polymer matrix composites. Nanoclay-reinforced epoxy-based GFRP showed significant improvement in properties including tensile, flexural, and hygrothermal properties, but only a moderate increase in impact performance ${ }^{52-54}$. Thus, the impact behavior of nanoclay reinforced by epoxy-based
GFRP nanocomposites is still a concern. The mechanical properties showed that with the addition of $2 \mathrm{wt} \%$ Cloisite $10 \mathrm{~A}$, the ultimate tensile strength and modulus of elasticity were increased. The ultimate tensile strength is increased due to the possibility of gallery delamination of the nanoclay. In addition, the orientation of the nanoclay along the possible tensile direction also results in a higher ultimate tensile strength at $2 \mathrm{wt} \%$. Thus, the ultimate tensile strength and modulus increase at $2 \mathrm{wt} \%$, which may be due to the interlude's better structure in it ${ }^{55}$.

Table 2 shows that the modulus of elasticity has increased by $5 \%$. The ultimate tensile strength has increased by $22 \%$ between the epoxy without the addition of Cloisite 10A and 2wt\% Cloisite 10A. However, it decreased for accumulations exceeding $2 \mathrm{wt} \%$ Cloisite 10A. This may be due to the low dispersion of the clay in the epoxy resin. In the clay/epoxy matrix suspension processing conditions, the addition of nanoclays will increase the viscosity of the matrix. This increased viscosity may be related to the resin's difficult degassing and allow small voids in the matrix suspension. This results in poor dispersion of the epoxy-clay mixture and creates sufficient agglomerates in the matrix mixture. These agglomerates affect the rate of dispersion of the clay/epoxy matrix, such as intercalation or exfoliation ${ }^{35}$. Norazura Ibrahim et al. ${ }^{56}$ reported similarly that the tensile strength and elongation of the nanocomposites increased at low clay content of $2 \mathrm{wt} \%$ and decreased almost linearly with increasing clay content.

Table 2. Shows the effect of adding Cloisite 10A of the elastic modulus and ultimate tensile strength epoxy resin panel Aluminum-Glass Fiber ${ }^{25}$.

\begin{tabular}{|c|c|c|c|}
\hline No. & $\begin{array}{c}\text { Cloisite } 10 \mathrm{~A} \\
(\mathrm{wt} \%)\end{array}$ & $\begin{array}{c}\text { Elastic Modulus } \\
(\mathrm{Gpa})\end{array}$ & $\begin{array}{c}\text { Ultimate Tensile Strength } \\
(\mathrm{Mpa})\end{array}$ \\
\hline 1. & 0 & 39.5 & 372 \\
\hline 2. & 1 & 40.3 & 396 \\
\hline 3. & 2 & 41.5 & 455 \\
\hline 4. & 3 & 40.4 & 410 \\
\hline 5. & 4 & 38.8 & 380 \\
\hline
\end{tabular}

H. Salam et al. ${ }^{26}$ produce mechanical properties such as tensile strength and tensile modulus of bioepoxy/nanocomposites clay, which are made according to Taguchi DoE and neat bioepoxies. Using high shear mixing and ultrasonication leads to better dispersion of the polymer chains into nanoclay platelets; thus, this resulted in improvements in mechanical properties ${ }^{26}$. The $3.0 \mathrm{wt} \%$ loading of the nanoclay was chosen because it resulted in optimal mechanical properties increase. However, exceeding $3 \mathrm{wt} \%$ decreases the tensile strength and fracture strain. This is because the higher the clay's loading, the higher the possibility of clay particle aggregation so that the clay group creates a stress enhancer, which lowers the tensile strength ${ }^{33}$. IPDA preserved nanocomposites had consistently higher tensile strength when compared to MTHPA at $0 \mathrm{wt} \%$ ESO content. Nanocomposites kept by IPDA 0 wt $\%$ ESO and loading $3 \mathrm{wt} \%$ Cloisite 10A (BC8) obtained a tensile strength of $34.47 \%$ and a tensile modulus of $50 \%$. Kabalan et al. reported that loading up to $3 \mathrm{wt} \%$ clay increased the tensile strength and modulus of young; however, if the clay exceeds $3 \mathrm{wt} \%$ or the addition of clay, the tensile strength, and modulus of young experience a decrease ${ }^{57}$.

\subsection{Cloisite 15A}

Different nanocomposite fillers can improve the mechanical, thermal, and electrical properties of epoxy resins ${ }^{58-61}$. The epoxy-based GFRP composite 
system reinforced with nanoclay can improve the resulting nanocomposites' tensile and flexural properties 37,62 . The tensile/flexural properties possessed by epoxy-based GFRP nanocomposites can be said to be superior. However, the impact strength is relatively low ${ }^{29,63,64}$. So it is necessary to strengthen the polymer fiber to increase its impact strength $29,63,64$. The results showed $1.0 \mathrm{wt}$. The $\%$ clay added to GFRP (i.e. E1C composite) resulted in an increase in impact strength by $13 \%\left(164 \mathrm{~kJ} / \mathrm{m}^{2}\right)^{30}$.

Nanocomposite surface modification has the potential to improve interface values and mechanical properties ${ }^{65}$. At the nanometer size for nanoclay, the interaction at the phase interface is significantly increased so that the material properties also increase. One of the main factors causing the properties in nanocomposites to change is when the ratio of surface area to volume increases ${ }^{30}$. As a result, more parts for bonding and the resulting better mechanical properties.

The TEM results (see Figure 2) show that the nanoclays were well dispersed in the composite system with exfoliated morphology. This enhancement of the properties of the nanoclay was achieved due to the ability of a nanoclay to undergo effective stress transfer in the morphology of the exfoliate. The exfoliated nanocomposites' morphology and the scattered clay provide a tortuous pathway and cause obstacles to crack propagation ${ }^{30}$. The impact strength experienced a maximum increase at 5.0 wt.\% with the EPDM gain without treatment by $27 \%$ (over NE). However, there was a $10 \%$ reduction in tensile strength and $14 \%$ in tensile modulus in the nanocomposite system compared to the reference sample (NE). So, treatment is needed on EPDM rubber's surface to increase the nanocomposites' impact strength further, namely using the silane treatment / MAH grafting before using EPDM. The results showed an increase in the nanocomposites' impact strength by $68 \%$ for a $\quad 5.0 \mathrm{wt} . \%$ EPDM concentration. However, the tensile properties of the nanocomposites were not significantly affected by the silane treatment on EPDM.
Epoxy-based glass fibers (NE) were used to strengthen the composite which was observed in the impact strength study of $161 \mathrm{~kJ} / \mathrm{m}^{2}$. The addition of 1 phr clay into the GFRP (E1C) system increased by about 4\% (167 kJ / m²) ${ }^{29}$. However, untreated polypropylene fibers, when added to the nanocomposite, caused a decrease in impact strength. The impact strength is decreased because polypropylene fibers and other composite systems elements are less suitable ${ }^{30}$.

The impact strength in a maximum increase of $44 \%$ contains polypropylene fibers with $2 \mathrm{phr}$ and silane treatment ${ }^{29}$. The impact strength is decreased when the polypropylene fiber composition is more than 2 phr. This is due to the low dispersion of polypropylene fibers due to the resin's high viscosity at high concentrations of polypropylene fibers ${ }^{30}$. In addition, the factor that affects the increase in the mechanical properties of epoxy-based composites is the increase in strain rate caused by the viscoelasticity of a polymer ${ }^{66}$. The tensile and flexural strengths of the composite system reinforced with epoxy-based glass fibers (NE) were observed to be $269 \mathrm{MPa}$ and 197 $\mathrm{MPa}$, respectively. The addition of $1 \mathrm{phr}$ clay to GFRP (E1C) increased tensile and flexural strength (16.5\% and $14.5 \%$, respectively, compared to NE). The increase was also shown by the tensile and bending modulus with an increase of $6.5 \%$ and $34.5 \%$, respectively ${ }^{29}$. The modulus and strength of failure can be improved by the presence of a cross-linked structure that results from processing the epoxy when it is cured, polymerized, and forms a highly crosslinked structure. However, the cross-linked structure can lead to increased brittleness, as a result of which the resistance to induction and crack propagation is low. It can worsen the impact strength of the composite ${ }^{67}$.

The XRD results show that for Cloisite $\AA$ 15A, the peak $\left(\mathrm{d}_{001}\right)$ was observed at $2 \theta=2.44^{\circ}$ corresponding to the d-spacing $36.16 \AA$. However, for E1C nanocomposites, the peak $\left(\mathrm{d}_{001}\right)$ did not indicate the morphology of the chipped nanoclay layer in the nanocomposite system.

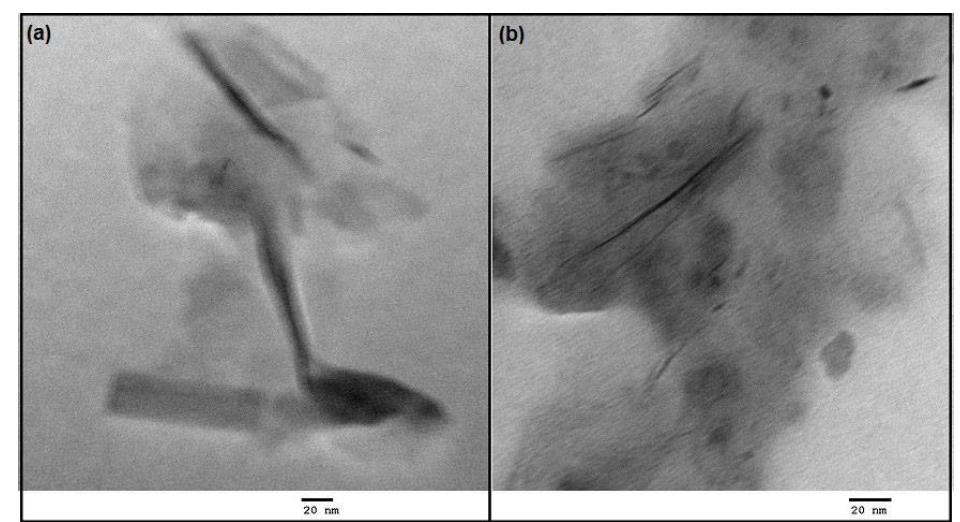

Figure 2. TEM micrographs showing exfoliated morphology at (a) one location and (b) at another location of EIC nanocomposite formulation ${ }^{30}$ 
Nanoscale fillers improve the performance of composites due to the unique intercalation / exfoliated characteristics ${ }^{68}$. Most of the clay morphology of the exfoliated and uniform dispersion can be confirmed by images TEM ${ }^{69}$. In Figure $2 \mathrm{a}$ - b, the TEM results show that the clay platelets are randomly aligned with a considerable distance between layers. This indicates a clay morphology that is exfoliated in the nanocomposite system.

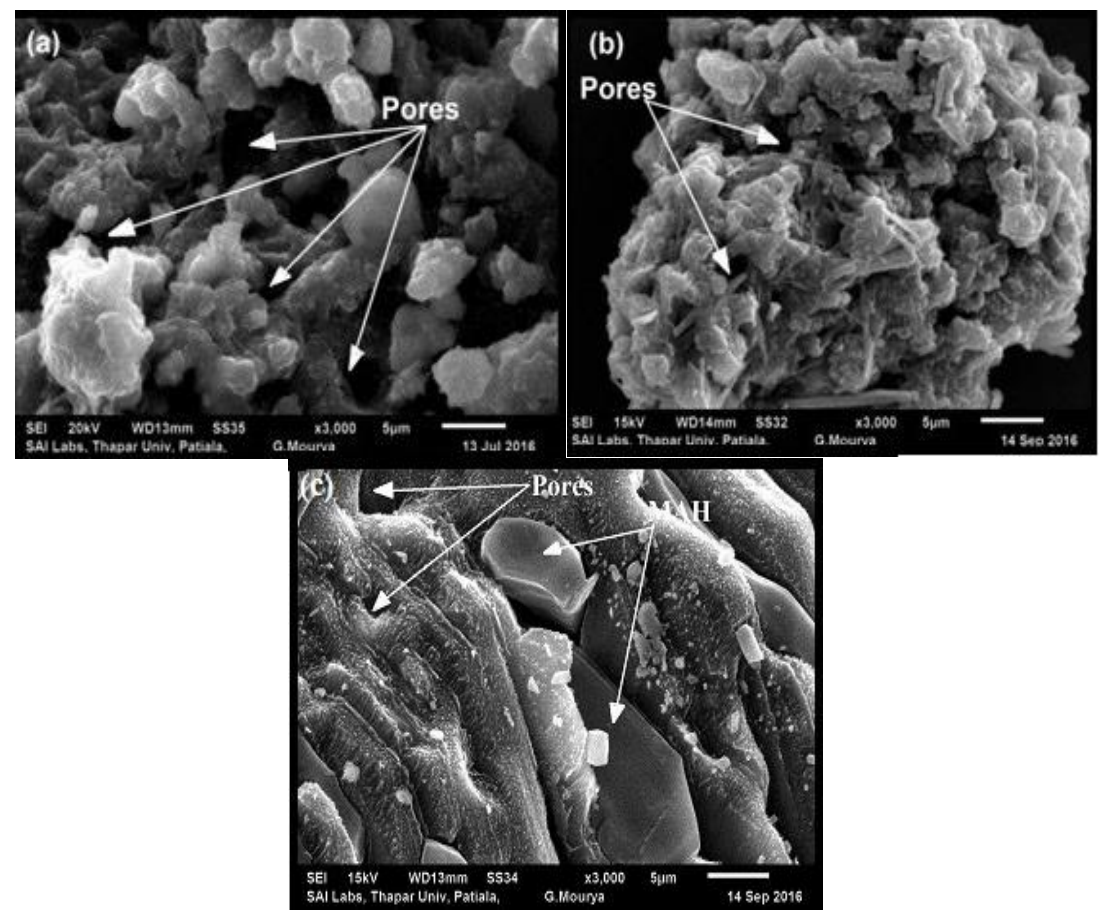

Figure 3. SEM micrograph of EPDM rubber (a) without treatment, (b) treated with silane, and (c) grafted with $\mathrm{MAH}^{30}$

It is observed that the SEM results in Figure 3 show that there are several large pores (Figure 3a). This is different from EPDM treated (silane treatment / MAH grafted), showing a reduced number and size of pores so that the morphology of EPDM rubber is relatively dense and is also caused by the presence of compatible substances (Figure 3b-c).

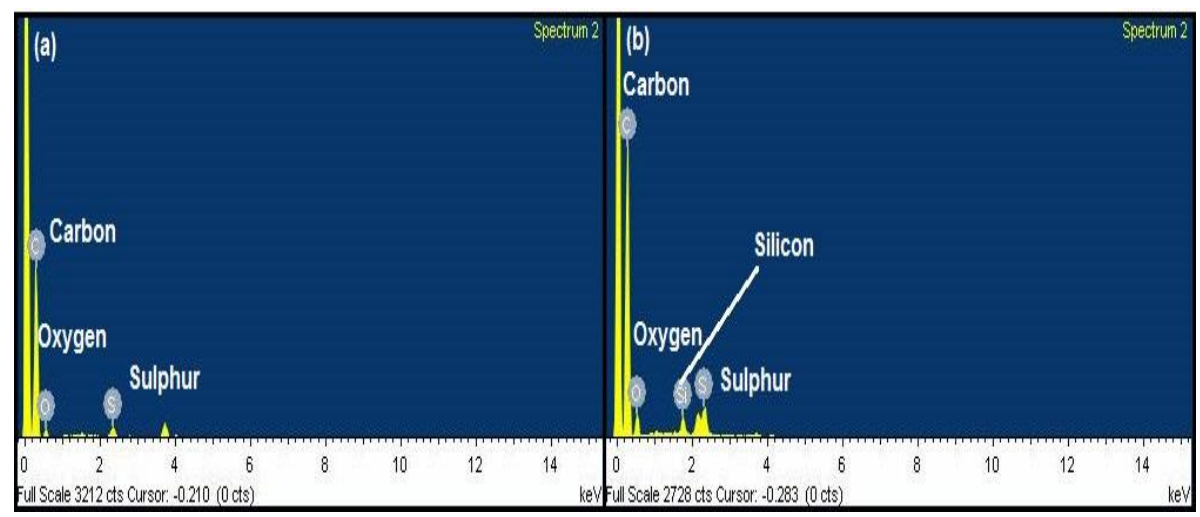

Figure 4. EPDM rubber EDS spectrum (a) untreated, and (b) treated silane ${ }^{30}$

The presence of silane on the EPDM surface (with/without treatment) can be confirmed by performing EDS. The EDS spectrum results in Figure $4 a, b$ show the presence of silicon in EPDM rubber (presence of silane), while the spectrum in EPDM rubber without treatment has no silicon (no silane). 

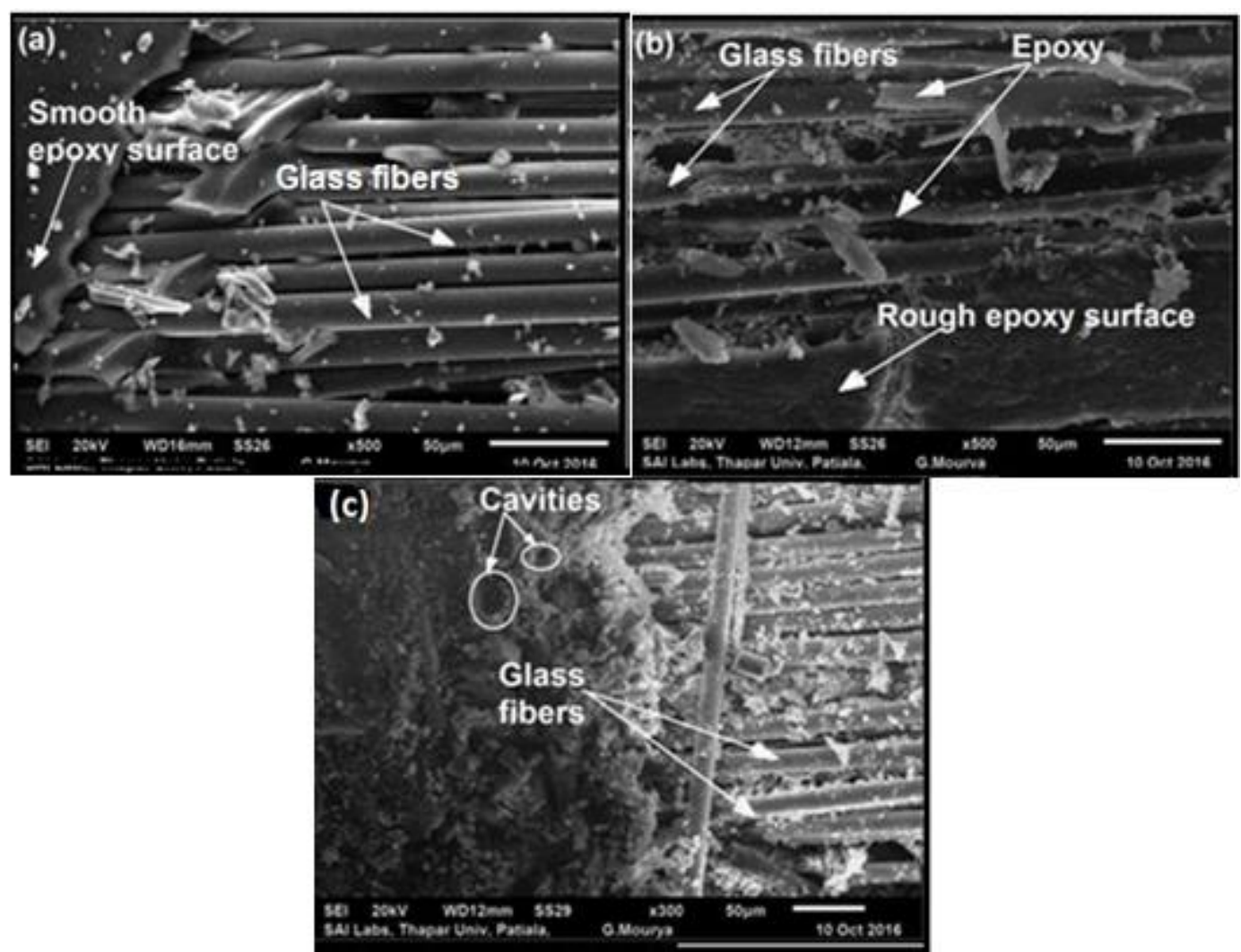

Figure 5. SEM micrograph of GFRP composite (a) without clay and EPDM (NE), (b) reinforced with 1.0 weight. \% clay (E1C), (c) reinforced with $5.0 \mathrm{wt} \% \%$ Untreated EPDM (E1C5R), (d) amplified by 5.0 wt. \% Silane treated EPDM (E1C5RS), and (e) reinforced with MAH grafted EPDM (E1C5 RMAH) ${ }^{30}$

SEM results for the NE composites (Figure 5a) showed the interface adhesion between the glass fiber, and the epoxy matrix was slight. The strong interfacial adhesion between the matrix and polymer will allow the transfer of stress from the matrix and the mechanical properties to be increased ${ }^{70}$. In addition, the cause of the low impact strength is the presence of brittle fracture resulting from the lack of resistance shown by the smooth epoxy surface. Figure $5 \mathrm{~b}$ shows a relatively rougher surface, resulting in high impact strength due to better resistance to impact loading. Cracks are formed due to mechanical energy, which brittle epoxy cannot correctly remove, resulting in excess pressure. The cracks spread rapidly through the epoxy, causing brittle damage. The tensile/flexural properties of epoxy-based GFRP nanocomposites are essentially very high ${ }^{67}$. A mechanism is needed to overcome the mechanical energy while limiting growth and breakdown in cavities to prevent early crack initiation, thereby increasing epoxy-based composites' toughness.
EPDM systems treated with silane at a concentration of 5.0 wt.\% (Figure 5c) showed better interface adhesion than EPDM systems without silane treatment. Hence, there was a further increase in impact strength. In addition, to improve interface adhesion, an effective method is used, namely MAH grafting ${ }^{71}$. This is in line with that reported by $\mathrm{Wu} \mathrm{X}{ }^{72}$ that the adhesion of the elastomeric interface with epoxy increased using silane. Silane agents are useful for increasing the compatibility of various material components. The silane agent can improve composite systems' compatibility because silane can react with the surface of organic and inorganic materials through covalent bonds ${ }^{29}$. One of the reactions of bonds silane depends on the number of reactive sites on the broken edges, gaps, or outer surface of the clay ${ }^{73}$. The different reactivity to organic or inorganic materials in silane can facilitate increased interface bonding of other clay material system elements ${ }^{74,75}$. Also, the addition of MAH to polypropylene fibers can increase the impact strength because the bonding of polypropylene that is grafted by MAH fibers to the epoxy matrix is better ${ }^{29}$. 

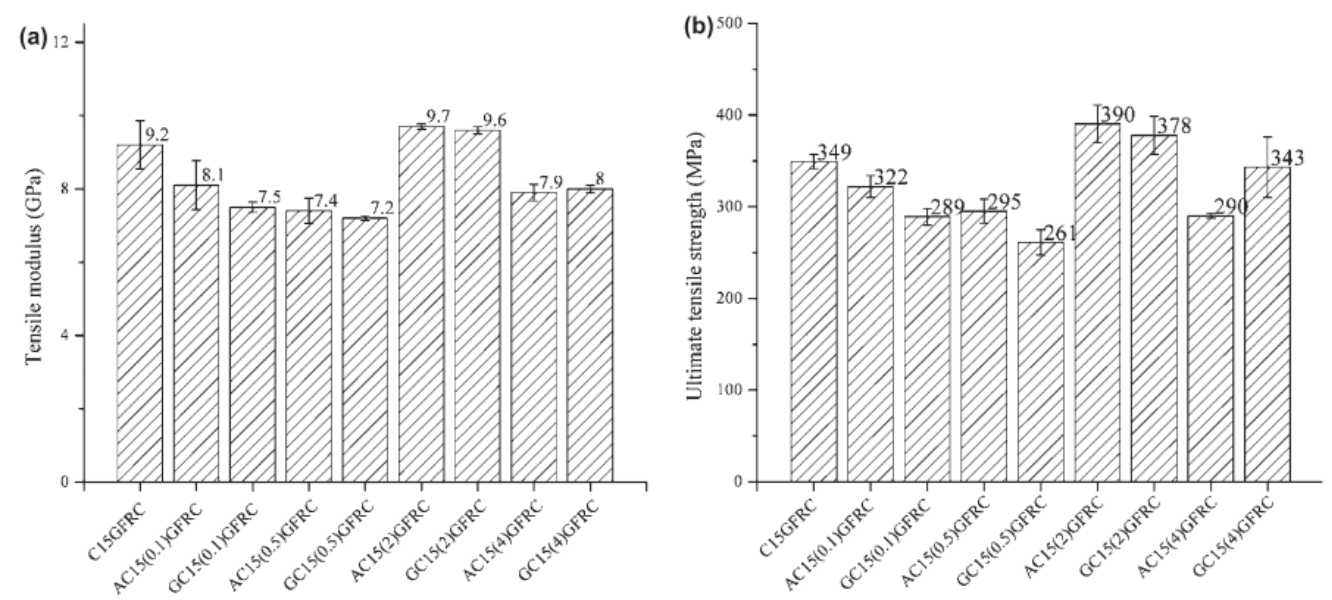

Figure 6. (a) and (b) Effect of clay modification on tensile properties ${ }^{31}$

The tensile modulus and strength for the composite system C15GFRC resulting from the study were 9.2 $\mathrm{GPa}$ and $349 \mathrm{Mpa}^{31}$. The tensile modulus and strength (Figure 6a-b) increased when the nanoclays treated with silane were used in the epoxy and glass fiber reinforced AC15 (2) composites resulting in a tensile modulus of $9.7 \mathrm{GPa}$ and tensile strength of $390 \mathrm{MPa}$. This increase was due to the significantly increased adhesion between silane and epoxy-treated clay and the curing reaction. In another case, the epoxy-coated with nano-silica also increased the adhesion of the nanocomposite system ${ }^{76}$.

The AC15 (2) GFRC sample appears to have a flaky morphology. It is characterized by a vast surface area that allows the polymer/filler to interact and increases the stress transfer's effectiveness between the nanoclay and the epoxy matrix. The interaction of functional groups in silane with clay and epoxy resin to form a network between the nanoclay and the epoxy matrix is getting stickier. In addition, the pickling factor that can increase the epoxy crosslinking can improve the mechanical properties of the nanocomposites.

The tensile modulus and strength values can decrease due to insufficient silane concentrations so that they cannot cover the vast surface area of the nanoclay dispersion in hydrolyzed silane. The polymer nanocomposites' properties are determined by the filler's diffusion in the polymer matrix and depend on the interaction between the filler and the polymer ${ }^{77}$. Nanoclays with higher concentrations can lead to better dispersion ${ }^{36}$. Dispersion in poor AC15 (4) GFRC due to clay sedimentation during processing and causing a decrease in the composites' strength. In addition, better dispersions can be obtained using vacuum evaporation after the addition of the preservative. After adding the preservative, vacuum evaporation removes the solvent entirely and produces a solid layer after drying ${ }^{78}$.

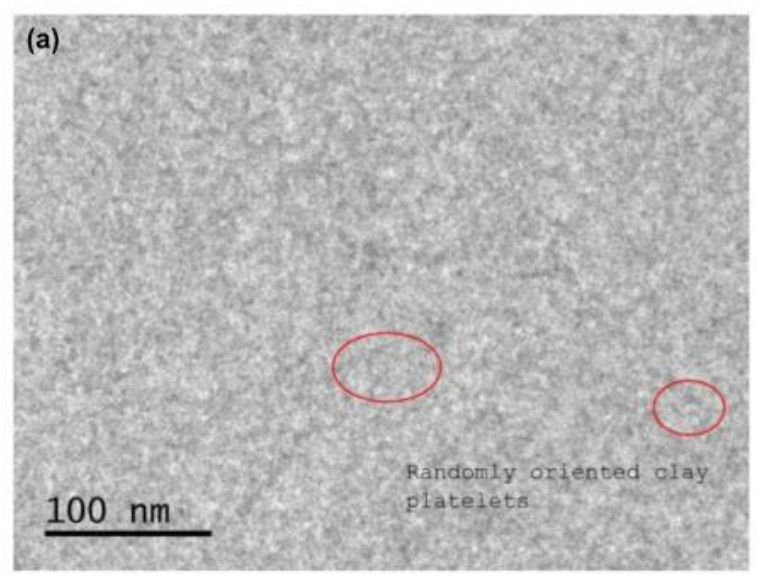

Figure 7. Transmission electron micrographs of AC15(2)GFRC ${ }^{31}$

Characterization was carried out for microstructure analysis of the spread of nanoclays on the epoxy matrix, the size and shape of the nanoparticles ${ }^{78-80}$. TEM results (Figure 7) show that the AC15 (2) GFRC nanocomposite system is mostly exfoliated, and the platelets are randomly scattered. The characteristics of Cloisite ${ }^{\circledR} 15 \mathrm{~A}$ peak at $2 \theta=2.41^{\circ}$ correspond to the d-spacing, $\mathrm{d}_{001}$, of $3.65 \mathrm{~nm}$ shifting to a lower angle indicating an increase in $\mathrm{d}_{001}$ distance of the Cloisite ${ }^{\circledR}$ $15 \mathrm{~A}$ nanoclay in epoxy. For fiber-reinforced nanocomposites and clay modification with silane showed no diffraction peaks in the $2 \theta=1.22^{\circ}$ and 
$2 \theta=1.49^{\circ}$ regions (the diffraction peaks of the nanocomposites without modification). This indicates that the clay is exfoliated. During processing, platelets from the clay have been released. Exfoliate clay is one of the main requirements for nanocomposites to have good mechanical properties.

\subsection{Cloisite 20A}

In the Ramakrishnan $\mathrm{S}$ et al. ${ }^{32}$ experiment, the results showed that the tensile properties of composites increased gradually with the addition of nanoclays up to $5 \%$ wt. This is due to nanoclay platelets' dispersion between the fibers and the matrix interface, which causes a strong interface bond between the fiber and matrix. However, if nano-clay is more than 5\%, it will reduce the tensile properties due to extensive accumulation in the composition. Higher tensile strength and tensile modulus 103.05MPa and 1.298 $\mathrm{GPa}$, respectively, were noted for composites having $5 \mathrm{wt} \%$ nano clay. The results obtained are by previous studies ${ }^{81,82}$. The increase in this modulus value is due to the increased adhesion between the fibers and the matrix, increasing the stress transfer between them, which increases the load-carrying capacity of the composite and also increases the Tensile strength. The addition of alkaline also causes the removal of hemicellulose and lignin from the fiber surface, resulting in micro-pore formation on the fiber surface. Also, during manufacture, the resin is impregnated into the fiber's micropores, thereby creating a strong physical interaction. In addition, the use of fibrous composites can also act as reinforcement ${ }^{83}$.

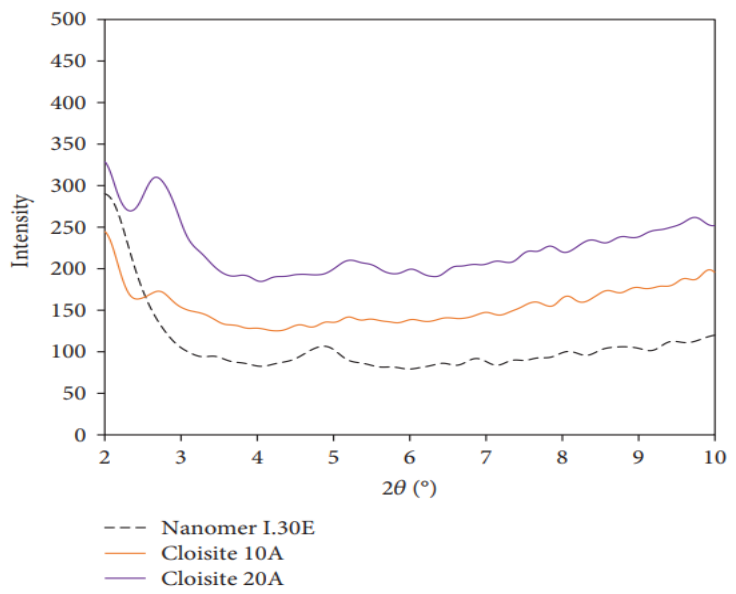

Figure 8. XRD spectra for UP/NC nanocomposites containing $3 \mathrm{wt} \%$ of different nanoclay types ${ }^{33}$

The X-ray diffraction pattern (XRD) was recorded to study nanoparticles' distribution in the polymer matrix ${ }^{84}$. In the research of Merah N. and Mohamed O. ${ }^{33}$ it is clear that the Cloisite nanoclays show diffraction peaks at a Bragg angle of $2.74^{\circ}$ (Figure 8). By knowing the diffraction angle at the peak, the distance between layers can be estimated using Bragg's law (equation (1)) ${ }^{85}$.

$\mathrm{n} \lambda=2 \mathrm{~d} \sin \theta$

Where $\mathrm{n}$ is an integer constant, assumed to be 1 in the case of principal reflection, $\lambda$ is the wavelength of the incident $\mathrm{X}$-rays, $\theta$ is the angle of scattering, and $\mathrm{d}$ is the planar or interlayer distance.

Thus, the d-spacing for the Cloisites is estimated to be $3.2 \mathrm{~nm}$, making the resulting structure intercalated. The addition of cloisite 20A produced acceptable results; namely, the increase in strength was $24 \%$ higher than that of UP. Similar conclusions can be drawn for fracture strain and stiffness. The increase in tensile properties is due to the high aspect ratio of the nanoclay and better monomer dispersion in the resin. Also, cloisite is modified octadecyl primary ammonium, which is an organic modifier. In addition, several styrene molecules may have been absorbed by the nanoclay platelets during mixing and sonication, leading to changes in cross-linking density. Apart from the mixing technique and the organic modifier's size, the nanocomposite's improvement is also influenced by the compatibility between the organic modifier and the monomer.

\subsection{Cloisite 25A}

Kumar et al. ${ }^{32}$. explained that the loading of Cloisite 25A from glass fibers reinforced with epoxy polymer with a clay content of $2 \mathrm{wt} \%$ has the best increase in the mechanical properties of ultimate tensile strength (UTS) and modulus the others. Because it has the highest increase in ultimate tensile strength and modulus young with a rise of $33.39 \%$ and $15.88 \%$, this can be seen in Figure 9. However, when the clay content exceeds $2 \mathrm{wt} \%$, its mechanical properties decrease. This can be due to mechanical and ultrasonic stirring, which cannot perfectly mix polymer and clay suspension, resulting in weak interfacial interaction between the nanoclay and polymer to decrease its mechanical properties. 


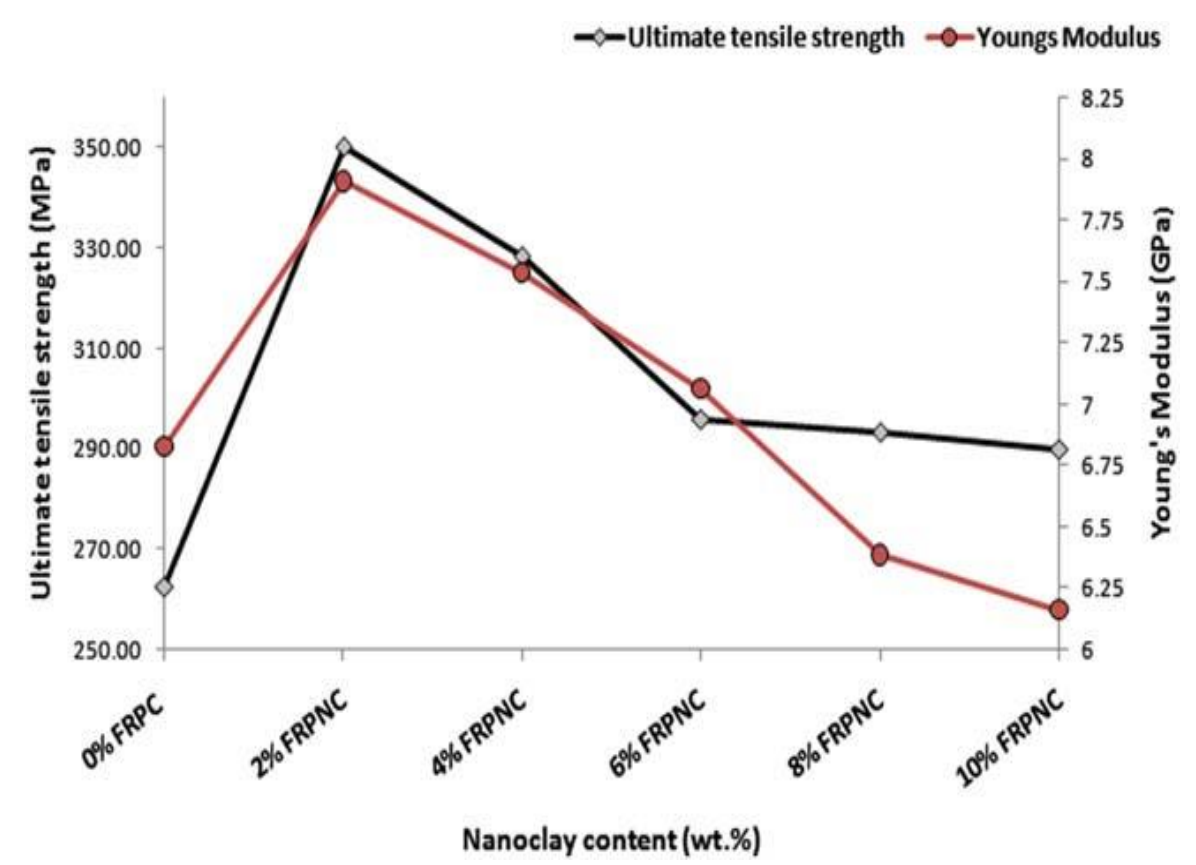

Figure 9. Ultimate tensile strength and Young's modulus of nanoclay filled nanocomposites ${ }^{32}$

Gurusideswar et al. ${ }^{86}$ stated that higher clay agglomerations. This can be explained in the image concentrations lead to the formation of clay below.
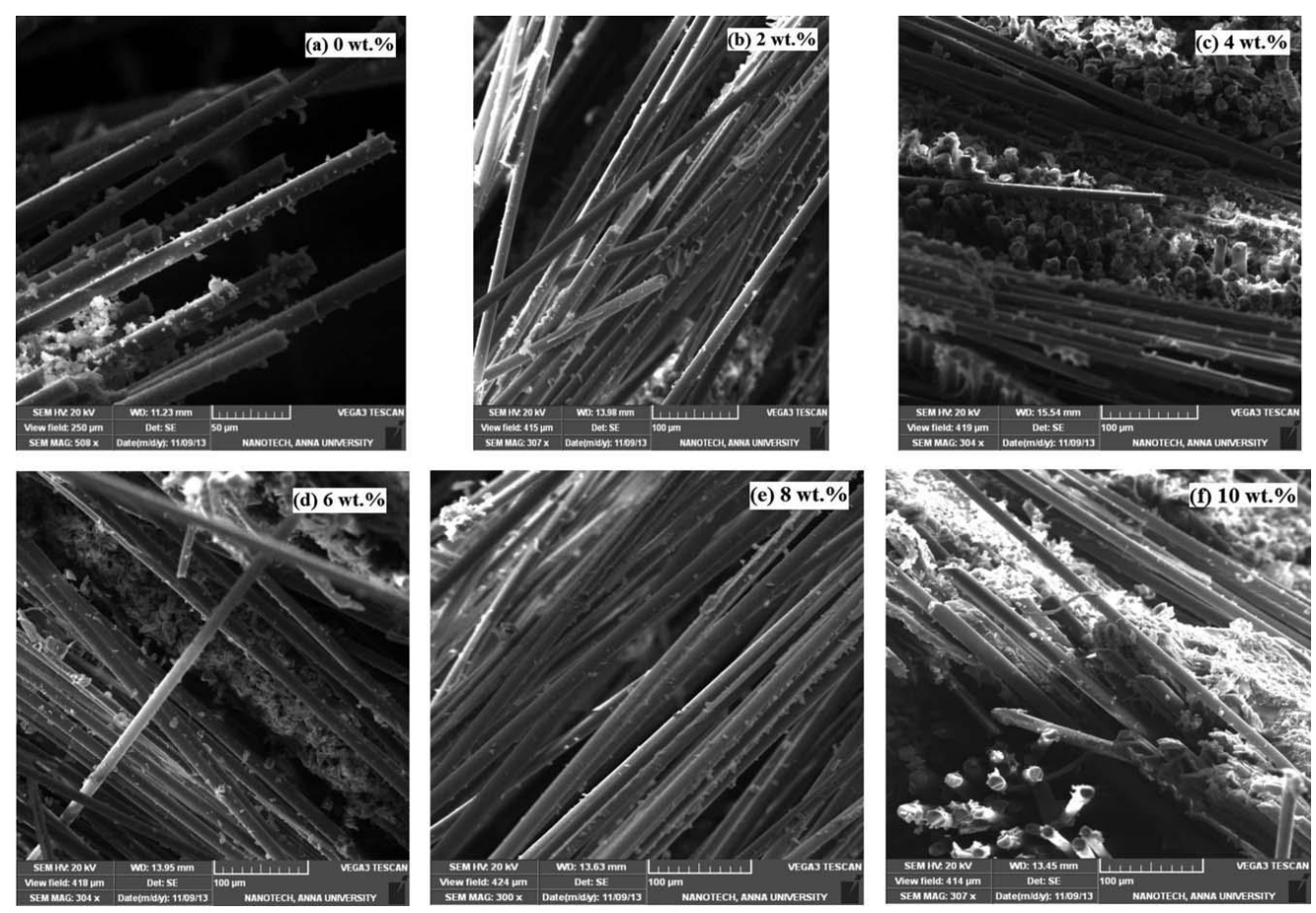

Figure 10. (a) - (f) Surface morphology of 0, 2, 4, 6, 8, and $10 \mathrm{wt} \%$ nanoclay filled nanocomposites ${ }^{32}$

In the Figure above, the sem test shows increased agglomeration. The formation of macro-sized nanoclay particles indicates an increase in accumulation. The agglomeration construction is due to the inhomogeneous mixing of the clay/epoxy/glass fiber mixture. This can be seen (Figure 10) in clay loading of more than $2 \mathrm{wt} \%$, which forms agglomeration.

Many studies had experienced an increase in the tensile modulus' mechanical properties and strength before the addition of higher clay. They decreased the mechanical properties after the addition of higher clay due to agglomeration. Some of the studies that occurred were in research Salam et al. ${ }^{87}$ with 5 wt $\%$ clay loading, Uwa et al. ${ }^{88} 3 \mathrm{wt} \%$, Sandchee et al. ${ }^{89}$ $1 \mathrm{wt} \%$, Nanda et al. ${ }^{54} 1.5 \mathrm{wt} \%$, Zappalarto et al. ${ }^{90}$ $5 \mathrm{wt} \%$, Gurusideswar et al. ${ }^{86} 3 \mathrm{wt} \%$, etc.

Kumar et al. ${ }^{35}$ explained that the loading of Cloisite $25 \mathrm{~A}$ with a clay content of $2 \mathrm{wt} \%$ had the best increase in mechanical properties at ultimate tensile strength 
(UTS), among others, with 5\%. This can be seen in (Figure 11a) The increase could be due to the excellent dispersion of the $2 \mathrm{wt} \%$ clay content. However, there was a decrease in the ultimate tensile strength (UTS) due to poor dispersion on subsequent increases. This can be explained by the increase in viscosity when adding clay. This increased viscosity is associated with the problematic degassing of the resin. This results in poor dispersion of the epoxy-clay mixture and creates sufficient agglomerates in the matrix mixture. These agglomerates affect the rate of
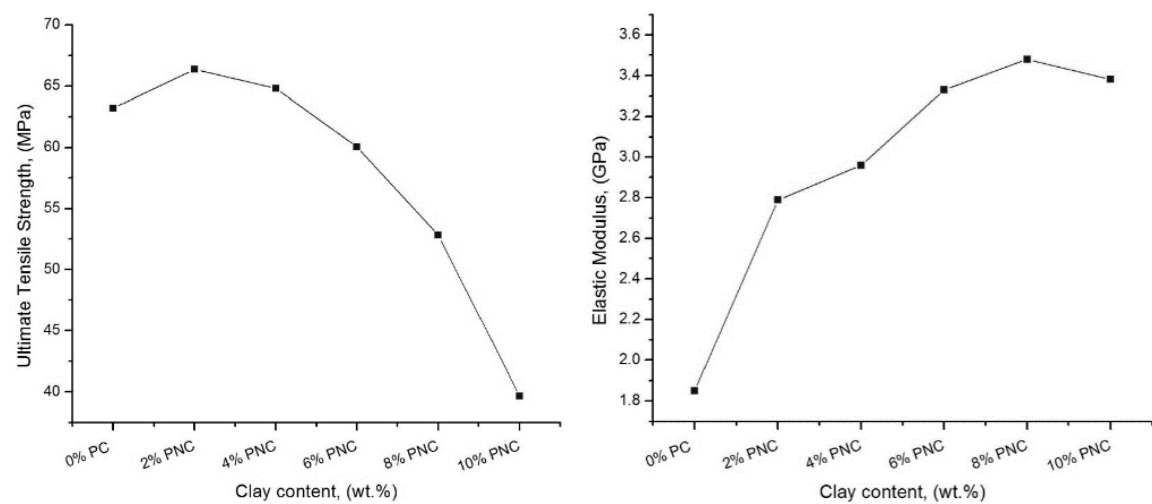

Figure 11. (a) UTS of Clay / Epoxy Nanocomposites and (b) Elastic Modulus of Clay / Epoxy Nanocomposites ${ }^{35}$
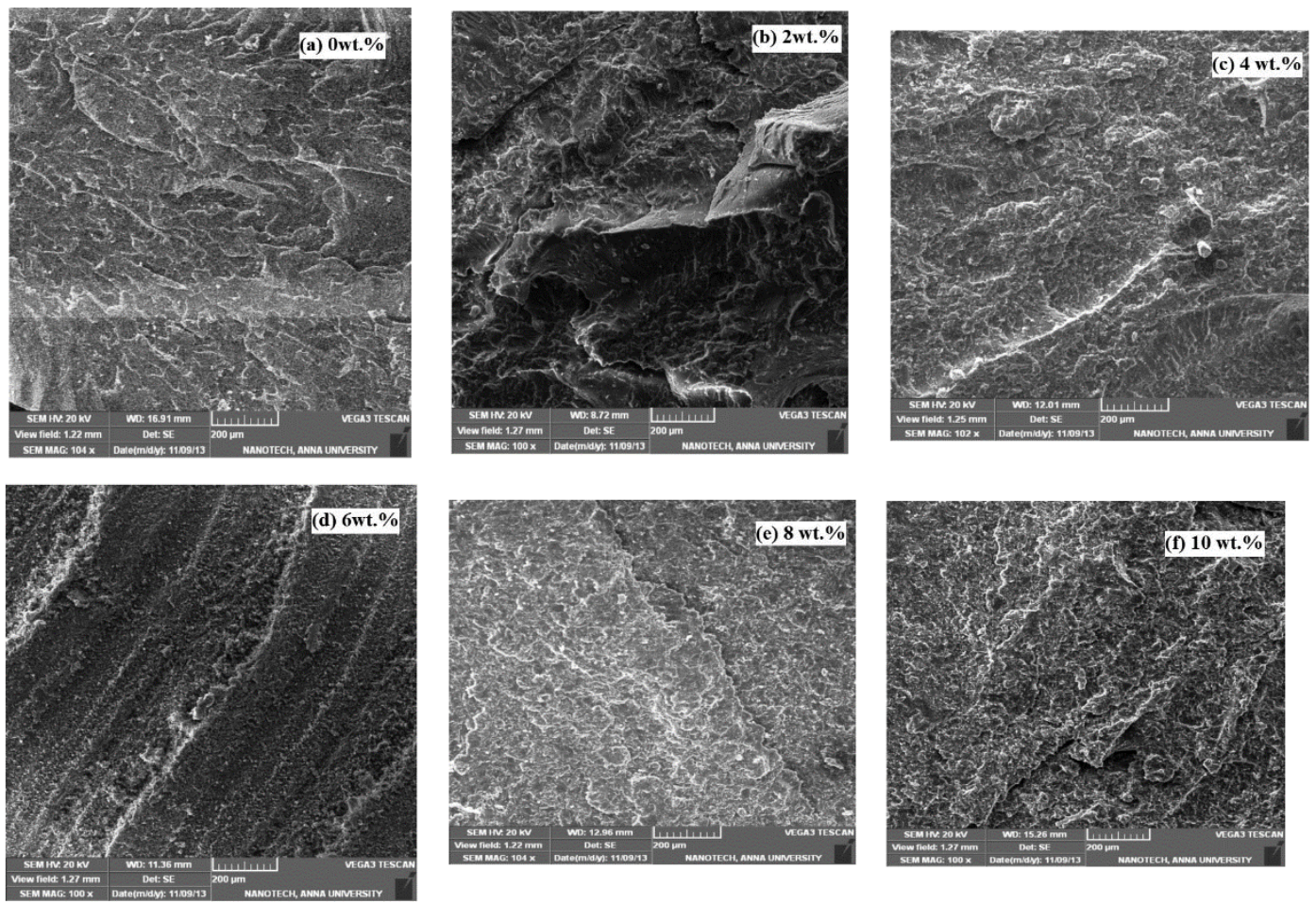

Figure 12. (a) - (f) Surface morphology of Clay / Epoxy Nanocomposites 35

The SEM image above shows a high surface wrinkle rate due to a nanoclay layer (Figure 12b-f). In (Figure 12b-d), you can see the surface is more even, which indicates that the clay is more finely dispersed with the resin because of the better epoxy-clay interaction. This effect provides good adhesion and interfacial interaction between polymer and clay. This reasonable blending rate offers high tensile strength, flexural strength, and impact strength at low content. Whereas in (Figure 12e-f), it can be seen that the surface is rougher, and the resulting cracks are quite a lot. This indicates a poor interface interaction between polymer and clay. This is due to the influence of increasing viscosity with the addition of clay. The 
high matrix viscosity limits the complete dispersion of nanoclays in the epoxy resin resulting in poor interface interactions between MMT clays and polymer. The high hardening effect at high nanoclay content results in less tensile strength, flexural strength, and impact strength. In (Figure 12b), the resulting cracks were less compared to the addition of other nanoclays so that the value of mechanical properties is better.

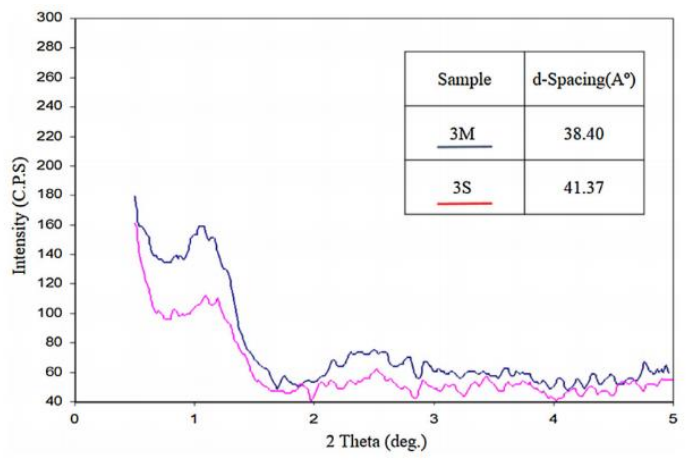

\subsection{Cloisite 30B}

Sharifi et al. ${ }^{36}$ have investigated the effect of adding Cloisite 30B to the anticorrosive coating from epoxy resin based on bisphenol-A (Epon resin 3003) with the melting method with an internal mixer and the solution method with a mechanical mixer. The samples prepared were nanocomposites with a concentration of $3 \mathrm{phr}$ nanoclay using the solution method (3S) and using the melting method, each with clay concentration of $1,3,5 \mathrm{phr}(1 \mathrm{M}, 3 \mathrm{M}$, and $5 \mathrm{M})$.

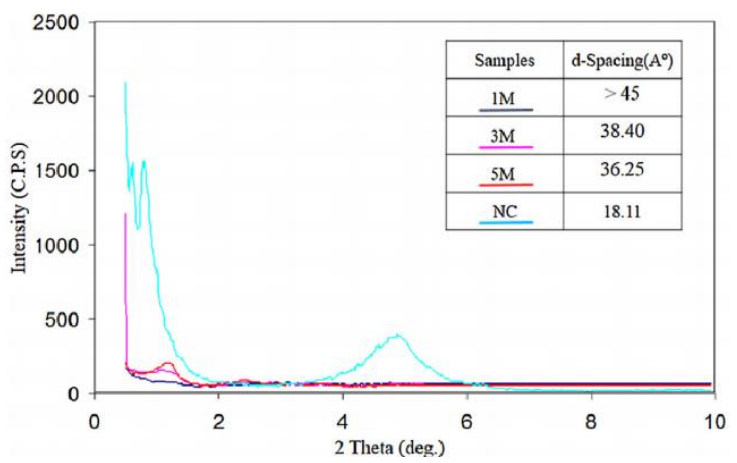

Figure 13. comparison of XRD patterns of different methods (a) and different clay concentrations in the melting method (b) ${ }^{36}$

XRD graph in Figure 13a shows an increase in dspacing (nanoclay blank $18.5 \AA$ ) in samples prepared by the melting or solution methods. The rise in dspacing indicates that the nanoclay can exfoliate or intercalate well in the epoxy matrix. The interaction between Cloisite 30B nanoclay and epoxy resin could come from the hydrophilic nature of Cloisite 30B modified with quaternary ammonium salt ${ }^{91}$. The d-spacing value of samples prepared with the solution method (41.37 $\AA$ ) was greater than that of samples prepared with the melting method ( $38.40 \AA$ ), meaning that the nanoclay was more easily diffused when using the solution method.

Epoxy resin solutions are non-Newtonian fluids. The viscosity can decrease with increasing shear rate due to partial deterioration of the physical interactions between the epoxy resin oligomers and their orientation in the flow direction. The rheological properties can be increased due to the epoxy oligomer's limited movement due to the physical interactions of epoxy-clay. The nanoclay dispersion in the polymer matrix also depends on the nanoclay dispersion at the microscale. The smaller the dispersed particles, the larger the aspect ratio and the more open surface for interfacial interactions with the polymer ${ }^{92}$. These reasons could be the cause of the ease with which nanoclays diffuse on the polymer epoxy matrix compared to using the melting method.

Then, the effect of nanoclay concentration can be seen in Figure 14 (b). It can be seen that the most significant increase in d-spacing occurred in the $1 \mathrm{M}$ sample. It seems that at higher concentrations of nanoclays, agglomeration is formed when it is incorporated into the epoxy matrix.
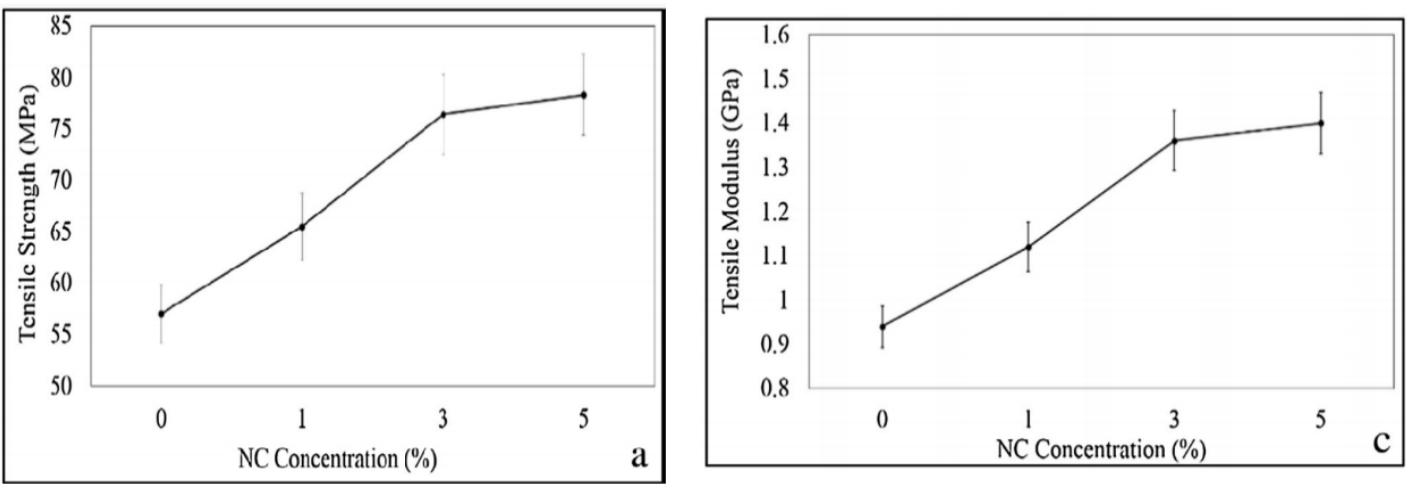

Figure 14. Graph of the increase in Tensile Strength (a) and Tensile Modulus (b) at different nanoclay concentrations ${ }^{36}$ 
Figure 14 above shows the increase in the tensile strength and modulus with increasing nanoclay concentration. A significant increase occurred in composites with a concentration of $5 \mathrm{phr}$. This increase in mechanical properties can be caused by the strong interaction between the silicate layer and the epoxy matrix and an intercalation/exfoliation structure ${ }^{93}$.

a)

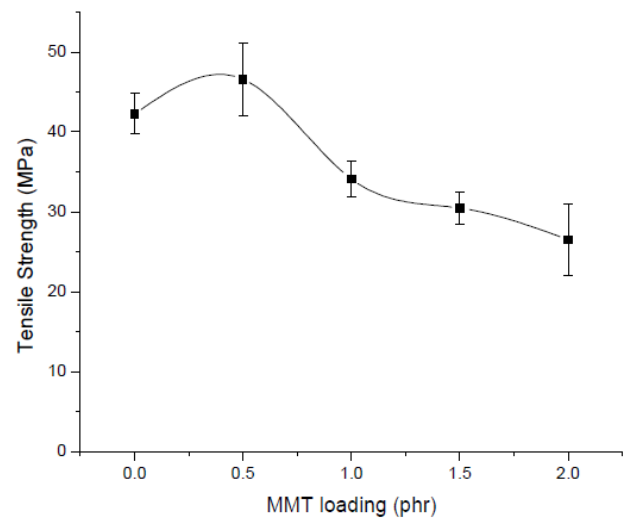

A study on the synthesis of nanocomposites with filler Cloisite 30B and Bio-based hardener has been carried out by Mustapha et al., ${ }^{37}$. Composite systems are made from DGEBA epoxy resin with biobased hardener Phenalkamines Cardolite NX-2003D as a curing agent. The method of manufacture is by sonication stirring and continued mechanically.

b)

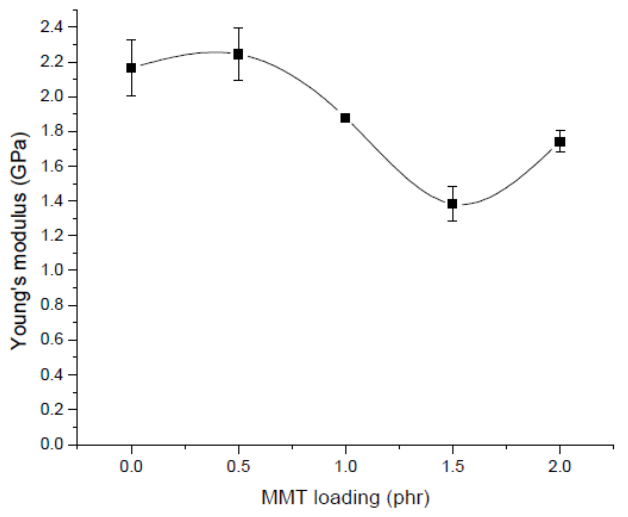

Figure 15. Graph of changes in Tensile Strength (a) and Tensile Modulus (b) at different nanoclay concentrations ${ }^{37}$

Figure 15a shows an increase in tensile strength to 46.6 $\mathrm{MPa}$ (tensile strength of neat epoxy resin: $42.3 \mathrm{MPa}$ ) at $0.5 \mathrm{phr}$; then, the value decreases with increasing concentration of nanoclay. The increase in this value indicates that the nanoclay can be dispersed well. Simultaneously, the decrease can be caused by a large amount of nanoclay content, which increases the epoxy resin's viscosity and caused microvoids because of the air traps. In addition, high agglomeration, along with the increasing concentration of nanoclay causes stress, which can reduce the tensile strength of the nanocomposites.

Tensile modulus is shown in Figure 15b. It can be seen that an increase in tensile modulus also occurs up to the concentration of $0.5 \mathrm{phr}$ nanoclay. An increase in tensile modulus at a concentration of $0.5 \mathrm{phr}$ reaches $4.65 \%$ increases due to the brittleness of the nature of nanoclay. However, the addition of the nanoclay concentration also decreased the tensile modulus value. This occurs due to the low dispersion or agglomeration of the nanoclay structure on the epoxy matrix. The matrix is blocked from entering the clay layer due to the too high concentration of the nanoclay.

\subsection{Cloisite 93A}

Cloisite $93 \mathrm{~A}$ is a type of clay that uses a methyl,

dehydrogenated tallow ammonium modifier agent ${ }^{94}$. Table 3 shows that the tensile modulus increases with the incorporation of clay 93A into the epoxy and $30 \%$ epoxy / TEIA mixture to $2.5 \%$ clay content. Tensile modulus of mixed nanocomposite at C93A $2.5 \%$ increased $44.2 \%$ compared to $30 \%$ epoxy / TEIA mixture. The nanocomposite modulus increased monotonically until a clay content of $2.5 \%$. The maximum modulus of $2515 \mathrm{MPa}$ was achieved at a clay content of $2.5 \mathrm{wt} \%$ in epoxy nanocomposites based on epoxy nanocomposites. The highest increase in tensile modulus can be considered as a good dispersion of nanoclay platelets. matrix ${ }^{5}$.

Table 3 also shows that the tensile strength increases with the incorporation of clay C93A into the epoxy and $30 \%$ epoxy / TEIA mixture until the clay content is $2.5 \%$. The tensile strength of the mixed nanocomposite at $2.5 \% \mathrm{C} 93 \mathrm{~A}$ increased by $63.6 \%$ compared to $30 \%$ epoxy / TEIA mixture. The increase in tensile strength is due to the exfoliation of clay platelets and strong interfacial adhesion between the silicate and epoxy matrix ${ }^{5}$. In Dagmar et al. study, the tensile strength curve shows that the Cloisite 30B nanofiller is more suitable for the PE/EVA copolymer type, while Cloisite 93A is more suitable for the EOC matrix type ${ }^{95}$.

Usually, the tensile modulus value is higher than the storage modulus, but trends show similar values, as shown in Table 4. Epoxy / PVAc samples with combined morphology have a tensile modulus identical to the pure epoxy. The tensile modulus value of epoxy / PVAc / C93A is higher than that of the epoxy / PVAc mixture, with an increase of $12-32 \%{ }^{37}$. 
Table 3. Tensile modulus and strength of pure epoxy, based on bio-blends, and nanocomposite matrix ${ }^{5}$.

\begin{tabular}{|c|c|c|}
\hline Sample & Tensile modulus (Mpa) & Tensile strength (Mpa) \\
\hline Epoxy & 1845.21 & 42.94 \\
\hline Epoxy/2.5\%C93 A & 1955.19 & 44.39 \\
\hline Epoxy/30\%TEIA & 2515.91 & 47.94 \\
\hline Epoxy/30\%TEIA/0.5\%C93 A & 2534.47 & 49.05 \\
\hline Epoxy/30\%TEIA/1.5\%C93 A & 2553.57 & 64.31 \\
\hline Epoxy/30\%TEIA/2.5\%C93 A & 2660.37 & 70.26 \\
\hline Epoxy/30\%TEIA/3.5\%C93 A & 2243.63 & 28.35 \\
\hline
\end{tabular}

Table 4 shows that there was a decrease in the tensile strength value at different $\mathrm{C} 93 \mathrm{~A}$ content. The tensile strength value increase is thought to be due to the strong adhesion between the composite material components. Therefore, the decrease in tensile strength in the epoxy/PVAc/C93A nanocomposite implies that the matrix and the organoclay's interfacial strength is weak. The transfer between the enhancement (clay) phase and the epoxy matrix is also less efficient. The presence of C93A nanoparticles increased the modulus of young but decreased the hardness of the epoxy/PVAc mixture and epoxy thermoset. Incorporating PVAc into the epoxy thermoset increases the hardness but causes a decrease in young modulus ${ }^{37}$.

Table 4. Tensile modulus and Tensile strength for epoxy / PVAc / C39A with different PVAc contents ${ }^{37}$.

\begin{tabular}{|c|c|c|c|c|}
\hline \multirow{2}{*}{ Wt\% PVAc } & \multicolumn{2}{|c|}{ Tensile modulus } & \multicolumn{2}{c|}{ Tensile strength } \\
\cline { 2 - 5 } & $0 \%$ clay & 4 wt\% C93A & $0 \%$ clay & 4 wt\% C93A \\
\hline 0 & $2.5 \pm 0.2$ & $2.8 \pm 0.1$ & $63 \pm 0.4$ & $54 \pm 3$ \\
\hline 5 & $2.4 \pm 0.2$ & $2.7 \pm 0.1$ & $62 \pm 3$ & $52 \pm 7$ \\
\hline 10 & $2.2 \pm 0.2$ & $2.9 \pm 0.1$ & $59 \pm 2$ & $56 \pm 4$ \\
\hline 100 & $4.1 \pm 0.5$ & & $37 \pm 3$ & \\
\hline
\end{tabular}

XRD can confirm the formation of exfoliated organoclay in nanocomposites ${ }^{5}$ and irregular intercalated nanococcal morphology ${ }^{96}$.

The XRD pattern for the C93A clay in Figure 16 shows 2 peaks at the diffraction angle 2 low from 2 to 10. The first peak $(001)$ is reached at $2=3.50$, connected by interlay spacing d001 $=1.26 \mathrm{~nm}$. The second peak (002) appears at $2=5.22$ corresponds to $\mathrm{d} 002=1.70 \mathrm{~nm}$ and the third peak appears at $2=6.50$ corresponds to $\mathrm{d} 003=2.04 \mathrm{~nm}$. The characteristics of these three peaks indicate the inhomogeneous structure of the clay platelet layers with different particle sizes. In other words, the XRD pattern of the DGEBA / 20\% ESO / 2.5\% C93A system did not show any detectable diffraction peaks. This confirms that the clay layer exfoliates well in the mixed matrix. It was thus improving its thermal and mechanical properties ${ }^{97}$.

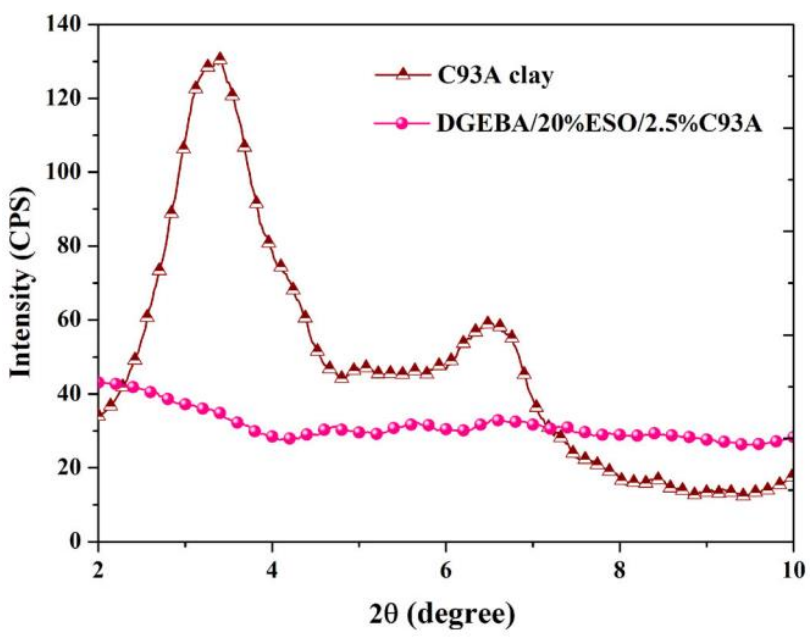

Figure 16. XRD patterns of C93A clay and DGEBA / 20\% ESO / 2.5\% C93A nanocomposite 5 
In contrast to the XRD pattern of EVA copolymers filled with 3 and 5\% clay, the exfoliation rate of MMT platelets was lower than that of Cloisite + EVA. This study can relate to the polyethylene portion of the EVA copolymer used because it is known that the different polarity of the polyethylene and MMT matrices leads to problems, and this requires thorough stirring with a whisk ${ }^{95}$. Meanwhile, in the research of Kabalan et al. ${ }^{57}$ The increase of basal d-spacing Cloisite 93A was due to the good interaction between the polymer chain and the modified clay surface. The relative intercalation (RI) decreased with increasing clay content from 1 to $5 \mathrm{wt} \%$, where the spacing of the PVA / Cloisite 93A sample at a loading rate of 1 wt $\%$ decreased from $48.5-39$ at a loading rate of 5 $\mathrm{wt} \%$ because the polymer gallery penetrated the filler decreased from 99 to $95 \%$ and clay content increases from 1 to $5 \mathrm{wt} \%{ }^{57}$.

The tensile modulus in Figure 17 shows that the nanoclay content of $2.5 \mathrm{wt} \%$ increases to $37 \%$. The Tensile modulus of ESO that was incorporated with DGEBA nanocomposites reached a maximum value of $2543 \mathrm{MPa}$ addition from the $2.5 \mathrm{wt} \%$ nanoclay. This results in a homogeneous dispersion of the nanoclay platelets into the mixed matrix. With the addition of C93A of more than $3.5 \mathrm{wt} \%$, it reduces the tensile modulus value, which affects the increase in viscosity and limits curing and the formation of microvoids ${ }^{39}$. These results are close to the results obtained by Avazverdi et al., Where the mechanical properties are highly dependent on the concentration of the nanofiller and polymer matrix ${ }^{98}$.

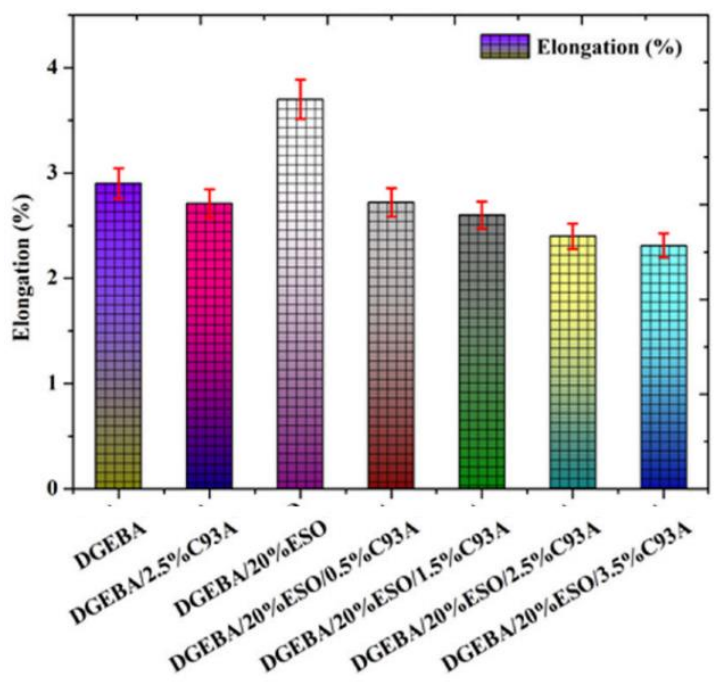

Figure 17. Mechanical properties of DGEBA, DGEBA / 20\% ESO blend and DGEBA / 20\% ESO / 2.5\% C93A nanocomposites ${ }^{39}$

Figure 18 shows that the tensile strength of the nanoclay content of $2.5 \mathrm{wt} \%$ increases to $67 \%$. The tensile strength increase led to strong interfacial interaction and a clay platelet calcification between the clay layer and the DGEBA / ESO matrix. The results showed that the polymer chains' flexibility was inhibited after incorporating the clay layer and had an effect on its strengthening. With the addition of C93A of more than $3.5 \mathrm{wt} \%$, it reduces the tensile strength value, which affects the increase in viscosity and limits curing and the formation of microvoids ${ }^{39}$.

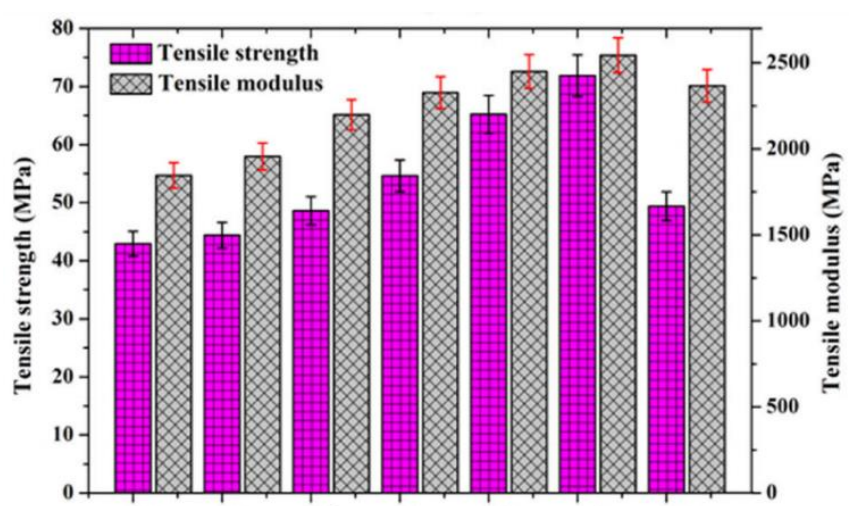

Figure 18. Tensile strength of DGEBA, DGEBA / 20\% ESO blend and DGEBA / 20\% ESO / 2.5\% C93A nanocomposites ${ }^{39}$ 
Figure 19 shows that the tensile strength and tensile modulus values for unfilled glass fiber reinforced epoxy composite (without nanoclay) are $270 \mathrm{MPa}$ and 7.1 GPa, respectively. As the nanoclay content is increased, the tensile strength increases. For the clay content of $5 \mathrm{wt} \%$, the tensile properties showed the maximum value. The tensile strength measured was $353 \mathrm{MPa}$, whereas the tensile modulus also showed an increasing 9.3 GPa. When compared with unfilled glass fiber reinforced epoxy composite, the addition of $5 \mathrm{wt} \%$ of nanoclay particles in the matrix showed a growing trend of about 23.66 and $23.58 \%$ for tensile modulus and tensile strength. Further increase in the Cloisite 93A nanoclay filler material decreases both the tensile modulus and tensile strength to the value of about and $8.1 \mathrm{GPa}$ and $302 \mathrm{MPa}^{40}$. The filler causes the maximum filling of voids in the matrix, and thus the saturation value was obtained for the tensile properties ${ }^{69,99}$.

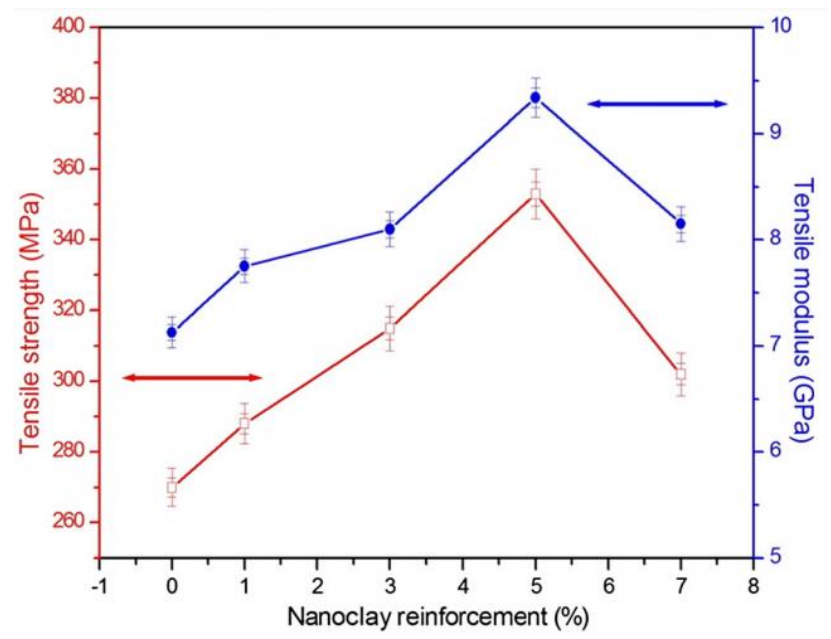

Figure 19. Effect of nanoclay weight percentage on tensile modulus and tensile strength ${ }^{40}$

Based on Figure 20, overall, the addition of organoclay to the epoxy matrix increases the d-spacing value for the types of Cloisite $\mathrm{Na}^{+}$, Cloisite $10 \mathrm{~A}$, and Cloisite 93A, with increasing spacing between layers respectively by 33,44 , and $40 \%$. Meanwhile, the d-spacing value of Cloisite 15 remains at the same level as Cloisite 15 itself. With an increase in spacing between layers by $6 \%$. This shows that the different clay intercalation levels are due to the cation exchange capacity (CEC) for different types of clay and curing agents. Interestingly, the d-spacing values of epoxy clay nanocomposites with Cloisite 15, Cloisite 10A, and Cloisite 93A were around $3.5 \mathrm{~nm}$. This shows that DGEBA molecules can only be swollen into the area between layers to increase the d-spacing value ${ }^{100}$. In the research of Wang et al., XRD found that unmodified nanoclays would not affect the crystal structure of the original composite material ${ }^{101}$.

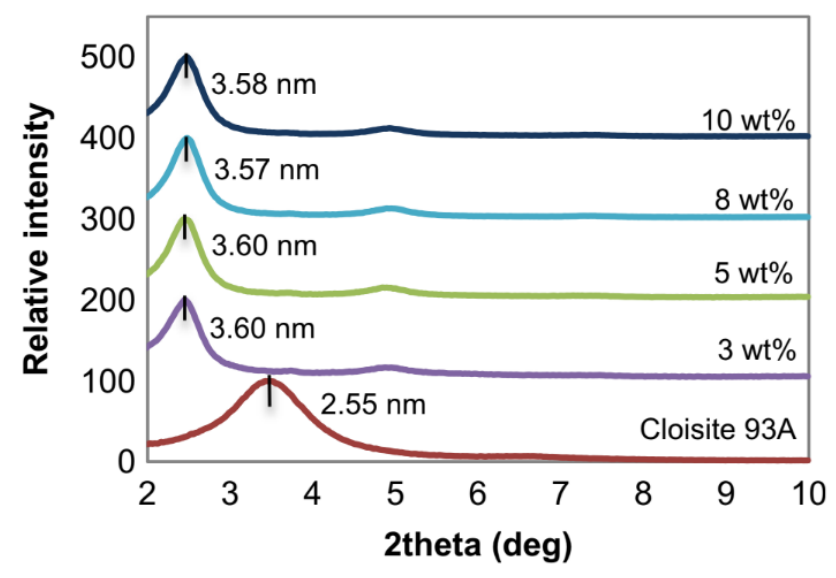

Figure 20. XRD pattern of epoxy/clay nanocomposites based on Cloisite $93 \mathrm{~A}^{100}$

\section{Conclusion}

Based on the results of literature studies, it can be concluded that the incorporation of Cloisite type nanoclay into the epoxy matrix improves the mechanical properties of epoxy-clay nanocomposites such as tensile modulus and strength. The most significant mechanical properties improvement was found in the Cloisite 93A type with the ultrasonic synthesis method or mechanical stirring. The quality of clay dispersion in an epoxy matrix depends on 
several factors; however, each technique positively affects the nanocomposite yield.

\section{Acknowledgment}

We Acknowledgement to Universitas Pendidikan Indonesia

\section{References}

1- M. Shettar, U. Achutha Kini, S. S. Sharma, P. Hiremath, Study on Mechanical Characteristics of Nanoclay Reinforced Polymer Composites, Mater Today Proc., 2017, 4, 11158-11162.

2- F. L. Jin, X. Li, S. J. Park, Synthesis and application of epoxy resins: A review, J Ind Eng Chem., 2015, 29, 1-11.

3- A. Saikia, N. Karak, Castor oil-based epoxy/clay nanocomposite for advanced applications, $A m \mathrm{~J}$ Eng Appl Sci., 2015, 9, 31-40.

4- Z. Ahmadi, Epoxy in nanotechnology: A short review, Prog Org Coatings, 2019, 132, 445-448.

5- S. Kumar, S. K. Samal, S. Mohanty, S. K. Nayak, Synthesis and Characterization of NanoclayReinforced Trifunctional "Bioresin-Modified" Epoxy Blends Enhanced with Mechanical and Thermal Properties, ChemistrySelect, 2017, 2, 11445-11455.

6- T. Ngo, Wet process and exfoliation of clay in epoxy, Korean Journal of Chemical Engineering, 2016, 33, 3550-3557.

7- K. Jlassi, I. Krupa, M. M. Chehimi, Overview: Clay Preparation, Properties, Modification, Elsevier Inc., 2017. doi:10.1016/B978-0-32346153-5.00001-X.

8- R. Babu Valapa, S. Loganathan, G. Pugazhenthi, S. Thomas, T. O. Varghese, An Overview of Polymer-Clay Nanocomposites, Elsevier Inc., 2017. doi:10.1016/B978-0-323-46153-5.00002-1.

9- M. Bhattacharya, Polymer nanocomposites-A comparison between carbon nanotubes, graphene, and clay as nanofillers, Materials (Basel), 2016, 9, 1-35.

10-S. Ashhari, A. A. Sarabi, Effects of Organically Modified Nanoclay Particles on the Mechanical Properties of Aliphatic Polyurethane/Clay Nanocomposite Coatings, Polymer Composites, 2015, 47, 1-8.

11-M. Karamane, M. Raihane, M. A. Tasdelen, T. Uyar, M. Lahcini, M. Ilsouk, Y. Yagci, Preparation of fluorinated methacrylate/clay nanocomposite via in-situ polymerization: Characterization, structure, and properties, J Polym Sci Part A Polym Chem., 2017, 55, 411-418.

12-M. Raji, M. E. M. Mekhzoum, A. K. Qaiss, R. Bouhfid, Nanoclay Modification and Functionalization for Nanocomposites Development: Effect on the Structural, Morphological, Mechanical, and Rheological Properties, Nanoclay Reinforced Polymer
Composites, 2016, 1-34. doi:10.1007/978-98110-1953-1_1.

13-L. Zhu, L. Wang, Y. Xu, Chitosan and surfactant co-modified montmorillonite: A multifunctional adsorbent for contaminant removal, Appl Clay Sci., 2017, 146, 35-42.

14-S. Ben Moshe, G. Rytwo, Thiamine-based organoclay for phenol removal from water, Appl Clay Sci., 2018, 155, 50-56.

15-R. Khatem, R. Celis, M. C. Hermosín, Cationic and anionic clay nanoformulations of imazamox for minimizing environmental risk, Appl Clay Sci., 2019, 168, 106-115.

16-Q. Beuguel, J. Ville, J. Crepin-Leblond, P. Mederic, T. Aubry, Influence of formulation on morphology and rheology of polypropylene/polyamide blends filled with nanoclay mineral particles, Appl Clay Sci., 2017, 147, 168-175.

17-B. Adak, B. S. Butola, M. Joshi, Effect of organoclay-type and clay-polyurethane interaction chemistry for tuning the morphology, gas barrier, and mechanical properties of clay/polyurethane nanocomposites, Appl Clay Sci., 2018, 161, 343-353.

18-B. Bhadran, D. Vijayan, N. George, C. S. Julie Chandra, P. M. Sabura Begum, R. Joseph, Reinforcing effect of organoclay in nitrile rubber - Effect of mill mixing and latex stage mixing, Appl Clay Sci., 2018, 165, 91-102.

19-B. R. Prado, J. R. Bartoli, Synthesis and characterization of PMMA and organic modified montmorillonites nanocomposites via in situ polymerization assisted by sonication, Appl Clay Sci., 2018, 160, 132-143.

20-C. Muñoz-Shugulí, F. J. Rodríguez, J. E. Bruna, M. J. Galotto, C. Sarantópoulos, M. A. Favaro Perez, M. Padula, Cetylpyridinium bromidemodified montmorillonite as filler in low density polyethylene nanocomposite films, Appl Clay Sci., 2019, 168, 203-210.

21-T. D. Ngo, M. T. Ton-That, Wet process and exfoliation of clay in epoxy, Korean J Chem Eng., 2016, 33, 3550-3557.

22-F. Javanbakht, B. Razavi, M. Salami-Kalajahi, H. Roghani-Mamaqani, M. Ommati, Fabrication of high thermal stable cured novolac/Cloisite 30B nanocomposites by chemical modification of resin structure, Polym Adv Technol., 2020, 31, 226-232.

23-T. Nakato, Y. Nakano, E. Mouri, Effects of the sol-gel transition of clay colloids on the spectroscopic behavior of cationic dye adsorbed on the clay particles, Appl Clay Sci., 2015, 118, 29-37.

24-W. Wang, F. Wang, Y. Kang, A. Wang, Enhanced Adsorptive Removal of Methylene Blue from Aqueous Solution by alkali-activated Palygorskite, Water Air Soil Pollut., 2015, 226, 1-13. doi:10.1007/s11270-015-2355-0.

25-M. Irani, M. Fan, H. Ismail, A. Tuwati, B. Dutcher, A. G. Russell, Modified 
nanosepiolite as inexpensive support of tetraethylenepentamine for $\mathrm{CO}_{2}$ sorption, Nano Energy, 2015, 11, 235-246.

26-O. Zabihi, M. Ahmadi, S. Nikafshar, K. Chandrakumar Preyeswary, M. Naebe, A technical review on epoxy-clay nanocomposites: Structure, properties, and their applications in fiber reinforced composites, Compos Part B Eng., 2018, 135, 1-24.

27-P. Mathivanan, S. Thiugnanam, Study on the Mechanical Characteristics of hybrid metal-fiber panels with resin-Cloisite 10A Mixture, International of Applied Engineering Research, 2018, 13, 16548-16551.

28-H. Salam, Y. Dong, I. J. Davies, A. Pramanik, Optimization of material formulation and processing parameters in relation to mechanical properties of bioepoxy/clay nanocomposites using Taguchi design of experiments, $J$ Appl Polym Sci., 2018, 135, 1-18.

29-K. Singh, T. Nanda, R. Mehta, Compatibilization of polypropylene fibers in epoxy-based GFRP/clay nanocomposites for improved impact strength, Compos Part A Appl Sci Manuf., 2017, 98, 207-217.

30-K. Singh, T. Nanda, R. Mehta, Addition of nanoclay and compatibilized EPDM rubber for improved impact strength of epoxy glass fiber composites, Compos Part A Appl Sci Manuf., 2017, 103, 263-271.

31-B. Sharma, R. Chhibber, R. Mehta, Effect of surface treatment of nanoclay on the mechanical properties of epoxy/glass fiber/clay nanocomposites, Compos Interfaces, 2016, 23, 623-640.

32-S. Ramakrishnan, K. Krishnamurthy, R. Rajasekar, G. Rajeshkumar, An experimental study on the effect of nano-clay addition on mechanical and water absorption behavior of jute fiber reinforced epoxy composites, J Ind Text., 2019, 49, 597-620.

33-N. Merah, O. Mohamed, Nanoclay and water uptake effects on mechanical properties of unsaturated polyester, J Nanomater, 2019, 2019, 1-12. doi:10.1155/2019/8130419.

34-M. S. Senthil Kumar, N. M. Sundara Raju, P. S. Sampath, M. C. P. Selvan, Influence of Nanoclay on Mechanical and Thermal Properties of Glass Fiber Reinforced Polymer Nanocomposites, Polymer Composite, 2016, 1-8.

35-M. S. Senthil Kumar, C. Pon Selvan, P. S. Sampath, K. Raja, R. Nair, Enhanced Mechanical Properties of Glass Fiber/Epoxy Composites using Nanoclay, Adv Sci Eng Technol Int Conf ASET, 2019, 1-9.

36-M. Sharifi, M. Ebrahimi, S. Jafarifard, Preparation and characterization of a highperformance powder coating based on epoxy/clay nanocomposite, Prog Org Coatings, 2017, 106, 69-76.

37-R. Mustapha, A. Razak Rahmat, R. Abdul Majid,
S. Noor Hidayah Mustapha, Mechanical and Thermal Properties of Montmorillonite Nanoclay Reinforced Epoxy Resin with Bio-Based Hardener, Mater Today Proc., 2018, 5 , 21964-21972

38-M. S. Cabezudo, M. G. Prolongo, C. Salom, M. A. Garcia del Cid, R. M. Masegosa, Ternary Nanocomposites: Curing, Morphology, and Mechanical Properties, Polym Compt., 2015, 1-12.

39-S. Kumar, S. Mohanty, S. K. Nayak, Nanocomposites of epoxidized soybean oil (ESO)-based epoxy (DGEBA) blends and clay platelets: cured with methyl-hexahydro phthalic anhydride crosslinker, J Macromol Sci Part A Pure Appl Chem., 2020, 57, 654-662.

40-R. Jeyakumar, P. S. Sampath, R. Ramamoorthi, T. Ramakrishnan, Structural, morphological and mechanical behavior of glass fibre reinforced epoxy nanoclay composites, Int J Adv Manuf Technol., 2017, 93, 527-535.

41- A. A. Javidparvar, R. Naderi, B. Ramezanzadeh, Epoxy-polyamide nanocomposite coating with graphene oxide as cerium nanocontainer generating effective dual active/barrier corrosion protection, Compos Part B Eng., 2019, 172, 363-375.

42-D. V. Amaral Ceretti, L. C. Escobar da Silva, M. do Carmo Gonçalves, D. J. Carastan, The Role of Dispersion Technique and Type of Clay on the Mechanical Properties of Clay/Epoxy Composites, Macromol Symp., 2019, 383, 1-10.

43-M. M. Ansari, A. Chakrabarti, Impact behavior of GFRP and Kevlar/epoxy sandwich composite plate: Experimental and FE analyses, J Mech Sci Technol., 2017, 31, 771-776.

44-D. Dhanapal, A. K. Srinivasan, N. Ramalingam, Role of POSS as Coupling Agent for DGEBA/GF Reinforced Nanocomposites, Silicon, 2018, 10, 537-546.

45-S. Jahandideh, M. J. S. Shirazi, M. Tavakoli, Mechanical and thermal properties of octadecylamine-functionalized graphene oxide reinforced epoxy nanocomposites, Fibers Polym., 2017, 18, 1995-2004.

46-D. J. Kwon, P. S. Shin, J. H. Kim, Y. M. Baek, H. S. Park, K. L. DeVries, J. M. Park, Interfacial properties and thermal aging of glass fiber/epoxy composites reinforced with $\mathrm{SiC}$ and $\mathrm{SiO}_{2}$ nanoparticles, Compos Part B Eng., 2017, 130, 46-53.

47-J. J. Lee, I. Nam, H. Kim, Thermal stability and physical properties of epoxy composite reinforced with silane treated basalt fiber, Fibers Polym., 2017, 18, 140-147.

48-S. Safi, A. Zadhoush, M. Ahmadi, S. P. R. Tehrani, Hybrid silane-treated glass fabric/epoxy composites: tensile properties by micromechanical approach, Iran Polym J., 2018, 27. doi:10.1007/s13726-017-0578-1.

49-T. Nanda, K. Singh, D. Shelly, R. Mehta, Advancements in multi-scale filler reinforced 
epoxy nanocomposites for improved impact strength: A review, Crit Rev Solid State Mater Sci., 2020, 1-49.

50-R. K. Prusty, D. K. Rathore, B. C. Ray, $\mathrm{CNT} /$ polymer interface in polymeric composites and its sensitivity study at different environments, Adv Colloid Interface Sci., 2017, 240, 77-106.

51-G. Mittal, K. Y. Rhee, V. Mišković-Stanković, D. Hui, Reinforcements in multi-scale polymer composites: Processing, properties, and applications, Compos Part B Eng., 2018, 138, 122-139.

52-N. G. Ozdemir, T. Zhang, I. Aspin, F. Scarpa, H. Hadavinia, Y. Song, Toughening of carbon fibre reinforced polymer composites with rubber nanoparticles for advanced industrial applications, Express Polym Lett., 2016, 10, 394-407.

53-K. Leelachai, P. Kongkachuichay, P. Dittanet, Toughening of epoxy hybrid nanocomposites modified with silica nanoparticles and epoxidized natural rubber, J Polym Res., 2017, 24. doi:10.1007/s10965-017-1202-y.

54-T. Nanda, G. Sharma, R. Mehta, D. Shelly, K. Singh, Mechanisms for enhanced impact strength of epoxy-based nanocomposites reinforced with silicate platelets, Mater Res Express., 2019, 6. doi:10.1088/20531591/ab1023.

55-D. J. Daniel, K. Panneerselvam, Mechanical and Thermal Behaviour of Polypropylene/Cloisite 30B/Elvaloy AC 3427 Nanocomposites Processed by Melt Intercalation Method, Trans Indian Inst Met., 2017, 70, 1131-1138.

56-N. Ibrahim, M. Jollands, R. Parthasarathy, Mechanical and thermal properties of meltprocessed PLA/organoclay nanocomposites, IOP Conf Ser Mater Sci Eng., 2017, 191. doi:10.1088/1757-899X/191/1/012005.

57-L. Kabalan, M. M. Zagho, M. J. Al-Marri, M. M. Khader, Experimental and theoretical studies on the mechanical and structural changes imposed by the variation of clay loading on poly(vinyl alcohol)/cloisite ${ }^{\circledR}$ 93A nanocomposites, $J$ Vinyl Addit Technol., 2019, 25, 172-181.

58-J. Guo, J. Long, D. Ding, Q. Wang, Y. Shan, A. Umar, X. Zhang, B. L. Weeks, S. Wei, Z. Guo, Significantly enhanced mechanical and electrical properties of epoxy nanocomposites reinforced with low loading of polyaniline nanoparticles, $R S C A d v$., 2016, 6, 21187-21192.

59-H. Gu, J. Guo, H. Wei, X. Yan, D. Ding, X. Zhang, Q. He, S. Tadakamalla, X. Wang, T. C. Ho, S. Wei, Z. Guo, Transparent anhydridecured epoxy nanocomposites reinforced with polyaniline stabilized nanosilica, J Mater Chem C, 2015, 3, 8152-8165.

60-H. Gu, C. Ma, J. Gu, J. Guo, X. Yan, J. Huang, Q. Zhang, Z. Guo, An overview of multifunctional epoxy nanocomposites, J Mater Chem C, 2016, 4, 5890-5906.
61-H. Gu, J. Guo, H. Wei, S. Guo, J. Liu, Y. Huang, M. A. Khan, X. Wang, D. P. Young, S. Wei, Z. Guo, Strengthened Magnetoresistive Epoxy Nanocomposite Papers Derived from Synergistic Nanomagnetite-Carbon Nanofiber Nanohybrids, Adv Mater., 2015, 27, 6277-6282.

62-F. Naya, C. González, C. S. Lopes, S. Van der Veen, F. Pons, Computational micromechanics of the transverse and shear behavior of unidirectional fiber-reinforced polymers including environmental effects, Compos Part A Appl Sci Manuf., 2017, 92, 146-157.

63-E. G. Koricho, A. Khomenko, M. Haq, L. T. Drzal, G. Belingardi, B. Martorana, Effect of hybrid (micro- and nano-) fillers on impact response of GFRP composite, Compos Struct., 2015, 134, 789-798.

64-S. Awang Ngah, A. C. Taylor, Toughening performance of glass fibre composites with coreshell rubber and silica nanoparticle modified matrices, Compos Part A Appl Sci Manuf., 2016, 80, 292-303.

65-S. X. Peng, S. Shrestha, Y. Yoo, J. P. Youngblood, Enhanced dispersion and properties of a two-component epoxy nanocomposite using surface-modified cellulose nanocrystals, Polymer, 2017, 112, 359-368.

66-J. Seaglar, C. E. Rousseau, Compressive evaluation of homogeneous and graded epoxyglass particulate composites, Mater Sci Eng C, 2015, 49, 727-734.

67-D. Flore, K. Wegener, D. Seel, C. C. Oetting, T. Bublat, Investigation of chemical ageing and its effect on static and fatigue strength of continuous fibre reinforced plastics, Compos Part A Appl Sci Manuf., 2016, 90, 359-370.

68-Y. Tian, H. Zhang, J. Zhao, T. Li, B. X. Bie, S. N. Luo, Z. Zhang, High strain rate compression of epoxy-based nanocomposites, Compos Part A Appl Sci Manuf., 2016, 90, 62-70.

69-G. J. Withers, Y. Yu, V. N. Khabashesku, L. Cercone, V. G. Hadjiev, J. M. Souza, D. C. Davis, Improved mechanical properties of an epoxy glass-fiber composite reinforced with surface organomodified nanoclays, Compos Part B Eng., 2015, 72, 175-182.

70-M. Garg, S. Sharma, R. Mehta, Pristine and amino-functionalized carbon nanotubes reinforced glass fiber epoxy composites, Compos Part A Appl Sci Manuf., 2015, 76, 92-101.

71-L. Bazli, A. Khavandi, M. A. Boutorabi, M. Karrabi, Correlation between viscoelastic behavior and morphology of nanocomposites based on SR/EPDM blends compatibilized by maleic anhydride, Polymer, 2017, 113, 156-166.

72-X. Wu, H. Liu, Z. Tang, B. Guo, Scalable fabrication of thermally conductive elastomer/boron nitride nanosheets composites by slurry compounding, Compos Sci Technol., 2016, 123, 179-186.

73-G. Bishwa Bidita Varadwaj, K. Parida, V. O. 
Nyamori, Transforming inorganic layered montmorillonite into inorganic-organic hybrid materials for various applications: A brief overview, Inorg Chem Front., 2016, 3 , 1100-1111.

74-M. Garg, S. Sharma, R. Mehta, Processing of Functionalized and Pristine Carbon Nanotube Epoxy Composites with Silane-Treated Glass Fiber, Mater Manuf Process., 2016, 31, 2044-2056.

75-B. Koohestani, I. Ganetri, E. Yilmaz, Effects of silane-modified minerals on mechanical, microstructural, thermal, and rheological properties of wood-plastic composites, Compos Part B Eng., 2017, 111, 103-111.

76-S. Palraj, M. Selvaraj, K. Maruthan, G. Rajagopal, Corrosion and wear resistance behavior of nano-silica epoxy composite coatings, Prog Org Coatings, 2015, 81, 132-139.

77-S. K. Srivastava, Y. K. Mishra, Nanocarbon reinforced rubber nanocomposites: Detailed insights about mechanical, dynamical mechanical properties, payne, and mullin effects, Nanomaterials, 2018, 8, 1-56.

78-T. A. Nguyen, H. Nguyen, T. V. Nguyen, H. Thai, X. Shi, Effect of nanoparticles on the thermal and mechanical properties of epoxy coatings, J Nanosci Nanotechnol, 2016, 16, 9874-9881.

79-M. D. Tomić, B. Dunjić, J. B. Bajat, V. Likić, J. Rogan, J. Djonlagić, Anticorrosive epoxy/clay nanocomposite coatings: rheological and protective properties, J Coatings Technol Res., 2016, 13, 439-456.

80-M. K. Madhup, N. K. Shah, N. R. Parekh, Investigation and improvement of abrasion resistance, water vapor barrier and anticorrosion properties of mixed clay epoxy nanocomposite coating, Prog Org Coatings, 2017, 102, 186-193.

81-K. Deepak, S. V. P. Vattikuti, B. Venkatesh, Experimental Investigation of Jute FiberReinforcedNano Clay Composite, Procedia Mater Sci., 2015, 10, 238-242.

82-H. Abdellaoui, H. Bensalah, M. Raji, D. Rodrigue, R. Bouhfid, A. el Kacem Qaiss, Laminated Epoxy Biocomposites Based on Clay and Jute Fibers, J Bionic Eng., 2017, 14, 379-389.

83-G. Daniel, B. Richard, A. Mckee, Dive into Deep Learning, J Chem Inf Model, 2019, 53, 1689-1699.

84-M. Kosari, S. M. A. Mousavian, S. M. Razavi, S. J. Ahmadi, M. Izadipanah, Polyurethane/clay nanocomposites reinforced with carbon and glass fibres: study of mechanical and thermal properties, and the effect of electron beam irradiation, Plast Rubber Compos, 2017, 46, 413-420.

85-H. Suryanto, Biokomposit Starch-Nanoclay: Sintesis dan Karakterisasi, Universitas Negeri Malang, 2019, 1-123.

86-G. Sivanarutchelvan, V. Ramachandran, High strain rate sensitivity of glass/epoxy/clay nanocomposites, $10^{\text {th }}$ international conference on composite and technology, 2016, 1-12.

87-H. Salam, Y. Dong, Property evaluation and material characterization of soybean oil-modified bioepoxy/clay nanocomposites for environmental sustainability, Mater Today Sustain, 2019, 5, 1-18.

88-C. A. Uwa, E. R. Sadiku, T. Jamiru, Z. Huan, Effect of Cloisite ${ }^{\circledR}$ 20A Reinforced Polypropylene Nanocomposite for Thermal Insulation, IEEE 10th Int Conf Mech Intell Manuf Technol ICMIMT 2019, 2019, 5-9.

89-S. S. Chee, dan M. Jawaid, The Effect of BiFunctionalized MMT on Morphology Thermal Stability, Dynamic Mechanical, and Tensile Properties of Epoxy/Organoclay Nanocomposites, Polymers, 2019, 11, 1-18.

90-M. Zappalorto, A. Pontefisso, A. Fabrizi, M. Quaresimin, Mechanical behaviour of epoxy/silica nanocomposites: Experiments and modelling, Compos Part A Appl Sci Manuf., 2015, 72, 58-64.

91-A. Dehghan, M. J. Zohuriaan-Mehr, A. Salimi, Rapid preparation of epoxy acrylate-clay nanocomposite: Simultaneous acrylation/nanoclay dispersion under ultrasonication, Prog Org Coatings, 2017, 108, 44-50.

92-M. Tomić, B. Dunjić, M. S. Nikolić, J. Maletaškić, V. B. Pavlović, J. Bajat, J. Djonlagić, Dispersion efficiency of montmorillonites in epoxy nanocomposites using solution intercalation and direct mixing methods, Appl Clay Sci., 2018, 154, 52-63.

93-A. Samariha, A. H. Hemmasi, I. Ghasemi, B. Bazyar, M. Nemati, Effect of nanoclay contents on properties of bagasse flour/reprocessed high-density polyethylene/nanoclay composites, Maderas Cienc y Tecnol., 2015, 17, 637-646.

94-H. Salam, Y. Dong, I. Davies, Development of biobased polymer/clay nanocomposites: A critical review, Fillers and reinforcements for advanced nanocomposites. Woodhead Publishing, 2015,101-132. doi:10.1016/B978-008-100079-3.00006-5.

95-M. Dagmar, T. Alice, K. Alena, Polyethylene/Ethylene Vinyl Acetate and Ethylene Octene Copolymer/Clay Nanocomposite Films: Different Processing Conditions and Their Effect on Properties, Polym Eng Sci., 2019, 59, 2514-2521.

96-A. Rafiq, N. Merah, R. Boukhili, M. Al-Qadhi, Impact resistance of hybrid glass fiber reinforced epoxy/nanoclay composite, Polym Test., 2017, 57, $1-11$.

97-R. S. Chen, S. Ahmad, S. Gan, Characterization of recycled thermoplastics-based nanocomposites: Polymer-clay compatibility, blending procedure, processing condition, and clay content effects, Compos Part B Eng., 2017, 
131, 91-99.

98-E. Avazverdi, M. Vandalvand, S. A. Javadinia, A. Shakeri, Evaluation of the Effect of Clay Nanoparticles on Mechanical Properties of Recycled Polyethylene, Prog Rubber, Plast Recycl Technol., 2016, 32, 99-110.

99-P. P. Binu, K. E. George, M. N. Vinodkumar, Effect of Nanoclay, Cloisite 15A on the Mechanical Properties and Thermal Behavior of Glass Fiber Reinforced Polyester, Procedia Technol., 2016, 25, 846-853.
100-H. Salam, Y. Dong, I. J. Davies, A. Pramanik, The effects of material formulation and manufacturing process on mechanical and thermal properties of epoxy/clay nanocomposites, 2016. doi:10.1007/s00170-016-8572-x.

101-C. Wang, X. Gao, Y. Li, Mechanical Properties Improvement of Nanoclay Addition Epoxy 3D Orthogonal Woven Composite Material, Fibers Polym., 2019, 20, 1495-1503. 